\title{
MINERALIZAÇÃO E IMŌOBILIZAÇÃO DO NITROGÊNIO EM SOLO SUPLEMENTADO COM TORTA DE FILTRO DE USINA DE AÇÚCAR DE CANA E CARBONATO DE CÁLCIO
}

SUELI DOS SANTOS FREITAS

Orientador: Dr. CAIO OCTÁVIO NOGUEIRA CARDOSO

Dissertação apresentada à Escola Superior de Agricultura "Luiz de Queiroz", da Universidade de São

Paulo, para obtenção do título de Mestre em Agronomia. Área de concentração: Microbiologıa Agrícola.

PIR ACICABA

Estado de São Paulo - Brasil

Novembro - 1985 
ii.

A minha mãe,

DEDICO . 
iii.

AGRADECIMENTOS

Ao Dr. Caio Octávio Nogueira Cardoso a introdução à pesquisa e o estímulo e a amizade de tantos anos.

Ao Dr. Eli Sidney Lopes, da Seção de Microbio logia do Solo do Instituto Agronōmico, a amizade e as sugestões .

Aos Drs. Otávio Antonio de Camargo e Heitor Cantarella, das Seções de Pedologia e Fertilidade do Solo e Nutrição de Plantas do Instituto Agronômico, as muitas suges tões 。

À Dră Violeta Nagai, da Seção de Técnica Expe rimental e cálculo do Instituto Agronồmico, o auxílio na aná lise estatistica.

Ao Instituto Agronômico.

$\bar{A}$ Escola Superior de Agricultura "Luiz de Quei roz"。

Ao Conselho Nacional de Desenvolvimento Científico e Tecnológico.

Ao Convênio IAC/MIC/STI/FUNAT.

E, finalmente, com muito carinho, aos companheiros todos da Seção de Microbiologia do Solo do Instituto Agronômico: citá-los nominalmente seria uma longa lista e agradecer-lhes à altura, impossível. 


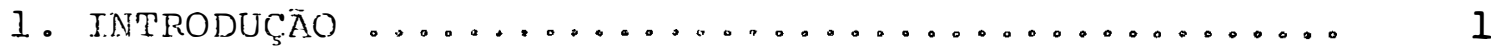

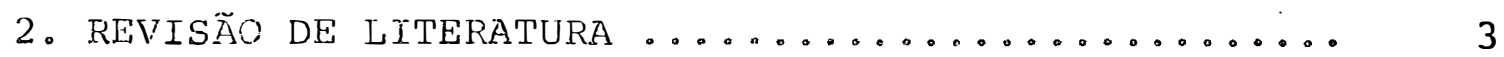

2.1. Efeito da Adição de Matéxia orgānica ao solo sobre a Mineralização e a Imobilização do Ni-

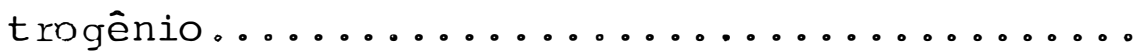

2.2: Efeito da Calagem sobre a Mineralização e a

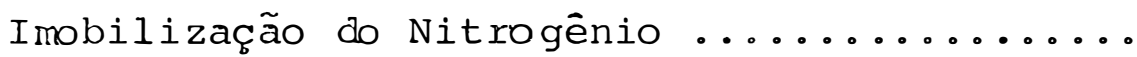

2.3. Efeito de Fatores do Ambiente sobre a nitrifí

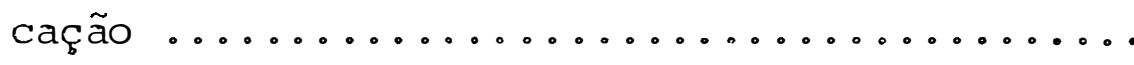

2.4 ע Efeito de Fatores do Ambiente sobre a Microflora atuante na Mineralização do Nitrogênio

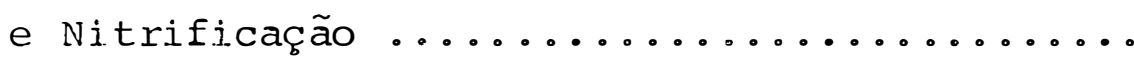

3.1. Teste da Metodologia para Quantificação dos Microrganismos Nitrificadores no solo ......

3.2. Efeito da Torta de Filtro e do C.aCo 3 sobre a Mineralização e à Imobilização do Nitrogênio do Solo e sobre a Nitrificação

3.3. Efeito da Torta de Filtro e do $\mathrm{CaCO}_{3}$ sobre a Mineralização e a Imobilização do Nitrogênio do Solo e sobre a Nitrificação, em Presença de Nitrogênio Adicionado 
3.4. Delineamento Experimental e Análises Estatís

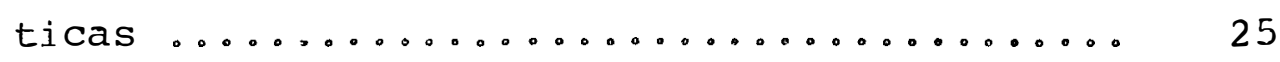

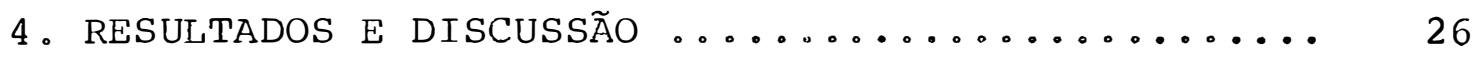

4.1. Teste de Metodologia para Quantificação dos Microrganismos Nitrificadores no Solo ...... 26

4.2. Efeito da Torta de Filtro e do $\mathrm{CaCO}_{3}$ sobre a Mineralização e Imobilização do Nitrogênio do Solo e sobre a Nitrificação ............. 30

4.3. Efeito da Torta de Filtro e do $\mathrm{CaCO}_{3}$ sobre a Mineralização e Imobilização do Nitrogênio do solo e sobre a Nitrificação, em presença de Nitrogènio Adicionado ................... 41

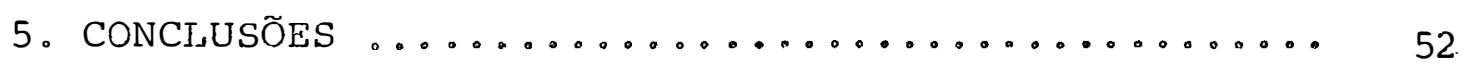

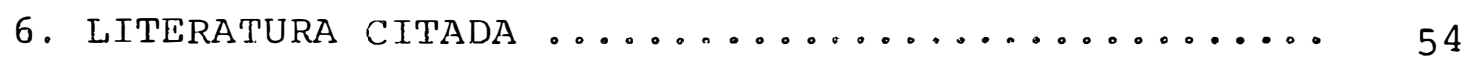

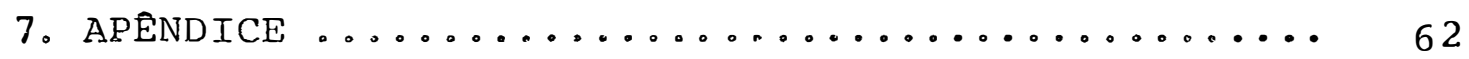


MINERAI,IZAÇÃOE IMOBILIZAÇÃO DO NITROGENIO EM SOLO SUPLEMENTADO COM TORTA DE FILTRO DE USINA

DE: AÇÚCAR DE CANA E CARBONATO DE CÁLCIO

Candidata: Sueli dos Santos Freitas Orientador: Dr. Caio Octávio Nogueira Cardoso

\section{R E S U M O}

Conduziram-se dois experimentos de incação de solo em casa de vegetação utilizando amostras de Latossolo Vermelho-Escuro, com o objetivo de estudar o efeito da aplicação do resíduo orgânico da indústria de açūcar e do carbonato de călcio sobre a mineralização e imobilização do nitrogênio no solo. o solo foi passado em peneira com malha de $2 \mathrm{~mm}$. Em um dos experimentos adicionou-se ao solo uma solução de $\mathrm{NH}_{4} \mathrm{NO}_{3}$ para fornecer $161 \mathrm{ppm}$ de $\mathrm{N}$ e no outro $\circ$ solo foi mantido natural. Em ambos os experimentos foram testados quatro tratamentos: sem e com adição de torta de filtro (equivalente a $40 \mathrm{t}$ de torta seca/ha), sem e com adição de $\mathrm{CaCO}_{3}$ (equivalente a $7,2 \mathrm{t} / \mathrm{ha}$ ). As amostragens foram feitas aos $0,10,30,50,70$ e 90 dias de incubação. Em cada amostragem analisaram-se os teores de ${\mathrm{N}-\mathrm{NH}_{4}^{+}}^{-}$e $\mathrm{N}^{-\mathrm{NO}_{3}^{-}}$e estimaram- 
-se os números mais prováveis de microrganismos amonificadores e nitrificadores.

No experimento sem adição de nitrogênio, nos tratamentos com torta de filtro o teor de ${\mathrm{N}-\mathrm{NH}_{4}^{+}+}^{+}{\mathrm{N}-\mathrm{NO}_{3}^{-}}^{-}$ após 10 dias de incubação foi praticamente zero, enquanto que nos tratamentos sem torta era $12 \mathrm{ppm}$. No tratamento com torta e sem $\mathrm{CaCO}_{3}$ esse teor zero de $\mathrm{N}-\mathrm{NH}_{4}^{+}+\mathrm{N}^{-\mathrm{NO}_{3}^{-}}$manteve-se pelos 90 dias que durou o experimento, enquanto que no trata mento com torta e com $\mathrm{CaCO}_{3}$ " após os 30 dias de incubação, esse teor subiu para aproximadamente $7 \mathrm{ppm}$, em média, manten do-se até o final do experimento.

No experimento com adição de nitrogênio, somente se observou efeito da torta na imobilização do nitrogê nio aos 50 e aos 90 dias de incubação. Nessas duas épocas, os tratamentos com torta apresentaram cerca de $2 / 3$ do teor de $\mathrm{N}-\mathrm{NH}_{4}^{+}+\mathrm{N}^{-\mathrm{NO}_{3}^{-}}$contido nos tratamentos sem torta $(250$ ppm, em média).

Em ambos os experimentos, não se detectou efeito significativo de qualquer dos tratamentos sobre as po pulações de microrganismos amonificadores e nitrificadores.

Também foi observada a ocorrência de nitrificação fotoquímica em meio de cultura para microrganismos nitrificadores, constatando-se a presença de $\mathrm{NO}_{2}^{-}$em meio com 
viii.

pleto em nutrientes e esterilizado, apös 2 semanas de incubação em condições de laboratório. 


\section{NITROGEN MINERALIZATION AND IMMOBILIZATION}

II SOII AMENDED WITH SUGAR MILI FILTER

AND CALCIUM CARBONATE

Candidate: Sueli dos Santos Freitas

Adviser: Dr. Caio Octávio Nogueira Cardoso

Two incubation experiments were carried out in

a greenhouse, with the objective of studying the effect of the application of a sugar cane-processing organic residue and of lime on mineralization and immobilization of nitrogen in soil. T'he soil used was a Red-Dark Latosol crusted to pass a 2 - mm sieve. In one experiment the soil was treated with solution containing $161 \mathrm{ppm} N$, and in the other, no $\mathrm{N}$ was added. In both trials four treatments were applied: with or without addition of Oliver-filter cake from sugar-cane mill (equivalent to $40 \mathrm{t} / \mathrm{ha}$ of dry cake), and with or without addition of $\mathrm{CaCO}_{3}$ (equivalent to $7.2 \mathrm{t} / \mathrm{ha}$ ). Samples were taken at $0,10,30,50,70$ and 90 days of incubation. The 
concentration of $\mathrm{NH}_{4}^{+}-\mathrm{N}$ and $\mathrm{NO}_{3}^{-}-\mathrm{N}$, and the most probable number of ammonifying and nitrifying microrganisms were evaluated in each sampling.

In the experiment with no $\mathrm{N}$ added, the concen tration of $\mathrm{NH}_{4}^{+}-\mathrm{N}$ plus $\mathrm{NO}_{3}^{-}-\mathrm{N}$ was practically zero after 10 days of incubation, where oliver-filter cake was applied, whe reas the concentration of these $\mathrm{N}$ forms increased to $12 \mathrm{ppm}$ in the treatments without cake. Application of oliver-filter cake without $\mathrm{CaCO}_{3}$ caused the concentration of $\mathrm{NH}_{4}^{+}-\mathrm{N} \quad$ plus $\mathrm{NO}_{3}^{-\mathrm{N}}$ to remain close to zero up to the end of the 90-dias in cubation period; with the addition of cake and $\mathrm{CaCO}_{3}$ the values of soil inorganic $N$ increased to an average of $7 \mathrm{ppm}$ and were kept constant until the end of the experiment.

In the trial in which $\mathrm{N}$ was added, the application of oliver-filter cake caused immobilization of $\mathrm{N}$ only after 50 and 90 days of incubation. In both these periods, the treatment with cake had about $2 / 3$ of the amount of $\mathrm{NH}_{4}^{+}-\mathrm{N}$ plus $\mathrm{NO}_{3}^{-}-\mathrm{N}$ that was present in the treatmemts without cake (average of $250 \mathrm{ppm}$ )。

In both experiments, application of filter ca ke and $\mathrm{CaCO}_{3}$ didn't increase significantly the population of ammonifying neither nitrifiers microorganisms.

Photochemical nitrification was observed in 
$x i$.

culture medium for nitrifying microorganisms; the presence of $\mathrm{NO}_{2}^{-}$in sterilized, nutrient complete medium was noticed after 2 weeks of incubation under laboratory condition. 
1. INTRODUÇÃO

A torta de filtro, resíduo da indústria álcool-açucareira, traz consigo o problema de sua disposição no ecossistema. Uma das recomendações é a sua disposição no solo, visando à diminuição dos gastos com fertilizantes (coPERSUCAR, s.d.). Quando se adiciona material orgânico ao solo o mesmo é mineralizado pela ação dos microrganismos, que liberam ao solo os elementos contidos no material em decomposição. Há intensa proliferação microbiana, uma vez que o car bono orgânico é fonte de energia para a maioria dos microrganismos (ALEXANDER, 1961). Com essa multiplicação, a população de microrganismos passa a requerer maiores quantidades de nutrientes para a formação de seu protoplasto, inclusive de nitrogênio. Ocorre que as plantas são más competidoras em relação aos microrganismos, sendo que estes satisfazem em primeiro lugar sua própria necessidade de nutrientes, liberan do para o solo apenas o nitrogênio em excesso. Esse fenômeno 
de conversão do nitrogênio mineral, ou de qualquer outro nutriente, 'a formas orgānicas retidas na biomassa dos microrga nismos é chamado imobilização microbiana (BARTHOLOMEW, 1965).

A imobilização ocorre simultaneamente com a mineralização, e ambas representam fenômenos opostos. A quan tidade de nitrogênio do material em decomposição é que determinará, primariamente, se ocorrerá liberação do nutriente para o solo ou sua imobilização na biomassa microbiana (BARTHOLOMEW, 1965). Pode mesmo ocorrer deficiência de nitrogênio para as plantas, dependendo do resíduo aplicado (ASGHAR e KANEHIRO, 1976). A torta de filtro, que tem em média 1,51\% de nitrogênio(COPERSUCAR, s.a..), encontra-se pouco acima da faixa crítica apontada por BATHOLOMEW (1965), que diz que resíduos com 1 a 1,3\% de nitrogênio podem ou não levar à imobilização desse nutriente.

O amônio liberado ao solo pela mineralização, além de estar sujeito à imobilização, também pode ser oxidado a nitrato, no processo denominado nitrificação.

o objetivo deste trabalho é verificar se ocorre imobilização de nitrogênio quando da adição de torta de filtro e $\mathrm{CaCO}_{3}$ ao solo, correlacionando-se esse processo com o número de microrganismos amonificadores presentes nesse so10, em diversas épocas de amostragem, bem como a variação numérica da população de nitrificadores. 
2.1 - Efeito da Adição de Matéria Orgânica ao Solo Sobre A Mineralização e Imobilização do Nitrogênio

A mineralização do nitrogênio contido em resí duos adicionados ao solo, uma vez que é levada a efeito por microrganismos do solo, ë influenciada por inúmeros fatores que afetam essa microflora, tais como: presença de oxigênio (BROADBENT e NAKASHIMA, 1970), concentração hidrogeniônica (JENSEN, 1929; EDMEADES et a $2 i i, 1981$ ), umidade (MYERS et alii, 1982), temperatura (CASSMAN e MUNN, 1980), quantidade de nitrogênio no resíduo incorporado (BROADBENT e NAKASHIMA, 1970) e quantidacle de micronutrientes no solo ou no resíduo (PREMI e CORNFIELD, 1969), entre outros.

A imobilização de nitrogēnio, ocorrendo simul taneamente à mineralização mas em sentido oposto, depende, 
em princípio, da quantidade de nitrogēnio do material em decomposição (BROADBENT e NAKASHIMA, 1970). BARTHOLOMEW (1965) afirma que resíduos com mais que 2\% de nitrogênio liberam es se nutriente para o solo, resíduos com 1 a $1,3 \%$ de nitrogēnio podem ou não levar à imobilização e resíduos com menos que $0,75 \%$ de nitrogênio podem exigir adição do nutriente para a sua decomposição. Alguns autores também se referem à realação carbono/nitrogênio $(\mathrm{C} / \mathrm{N})$ do material. Todavia, Nor man (1933), citado por BARTHOLOMEW (1965), assinala que "a decomposição depende diretamente da relação $\mathrm{C} / \mathrm{N}$ do material somente no caso incomum de todo o carbono e todo o nitrogènio serem prontamente disponíveis". Contudo, essa forma de expressão continua sendo usada, sem que se comprometam as in ferências feitas.

De qualquer maneira, a taxa de mineralização é o fator primário que controla a disponibilidade do nitrogê nio (CASSMAN e MUNN, 1980), dependendo da predominância de um dos dois processos, mineralização e imobilização, sobre o outro.

A adiçăo de materiais orgânicos ao solo estimula a decomposição da matéria orgânica do próprio solo (BROADBENT e NAKASHIMA, 1974). Nesse caso, o nitrogênio do solo também é mineralizado e tornado disponível às plantas, processo que pode ser acentuado pela adição de fertilizantes 
nitrogenados, segundo GANRY et alii (1978). Os mesmos autores consideram que o nitrogênio do solo tem um papel pelo me nos tão importante quanto o do fertilizante nitrogenado sobre a produtividade. WÓJCIK-WOJTKOWIAK (1978) observou que a mineralização do nitrogênio do solo foi mais rápida e em maior quantidade que a do contido em palha de aveia, incorporada em quantidade equivalente a $20 \mathrm{t} / \mathrm{ha}$.

A predominância da imobilização pode levar as plantas a deficiência de nitrogênio (ASGHAR e KANEHIRO,1976), tendo sido observada nas mais diferentes condições. O nitrogênio imobilizado na biomassa microbiana pode ser remineraliza do. Assim, a adição de materiais que favoreçam a imobilização poderia ser interessante, na medida em que o nitrogênio seria liberado lentamente. FOR'UUN e HERNANDO (1981a, 1981b) obtiveram maiores rendimentos de sorgo e cevada pela aplicação de $6.000 \mathrm{~kg}$ de palha de cereais por hectare complementada com $60 \mathrm{~kg}$ de $\mathrm{N} / \mathrm{ha}$, quando comparado a tratamentos sem adi ção de palha, atribuindo os benefícios obtidos à lenta liberação do nitrogênio imobilizado. No entanto, a liberação do nitrogênio imobilizado nem sempre pode ser esperada dentro de curtos intervalos de tempo (STOJANOVIC e BROADBENT,1956): a incorporação de cerca de 67 toneladas de restos de cultura de abacaxi por hectare, com relação $C / N=95,9$, resultou na diminuição da quantidade de nitrogênio disponivel no solo 
durante as primeiras 23 semanas de incubação, só vindo a aumentar durante as 12 ültimas semanas (TAM e MAGISTAD, 1936); é claro que a relação $\mathrm{C} / \mathrm{N}$ do material incorporado era alta, sendo esperado imobilização. KANAMORI e YASUDA (1979) apontaram $\mathrm{C} / \mathrm{N}=20$ como senco a relação crítica acima da qual há imobilização. Esses mesmos autores, entretanto, adicionando turfa e Nmineral ao solo, acharam de pequena magnitude a transformação do nitrogênio adicionado a nitrogênio orgânico, concluindo que a turfa não é facilmente decomponível por microrganismos. Isso confirma o conceito expresso por Norman (1933), citado por BATHOLOMEW (1965), de que a decomposição do material orgânico depende da aisponibilidade do carbono e do nitrogēnio. Parece ter sidc esse o fatōr que levou à lenta mineralizaçã̃o do nitrogênio contido em cevada observada por BROADBENT e NAKASHIMA (1974), que adicionaram o equivalen te a 20 t de parte aérea de cevaòa por hectare, com uma relação $C / N=17,1$, isto é, abaixo da relação anteriormente mencionada como crítica, e observaram que apenas $46 \%$ do nitrogênio foi mineralizado em cinco anos.

A incorporação de palha pode resultar, em alguns casos, em menor eficiência do fertilizante mineral nitro genado (GANRY et alii, 1978), devido à imobilização, existindo efeito favorável da adição de nitrogênio sobre a decomposi fão da matéria orgânica incorporada

(WŐJCIK-WOJTOKOWIAK, 1978). KANAMORI e YASUDA (1979) incorporaram palha de arroz 
$(\mathrm{C} / \mathrm{N}=56)$ ao solo, isoladamente ou suplementada com $\mathrm{NO}_{3}^{-}$suficiente para baixar a relação $\mathrm{C} / \mathrm{N}$ para 25 ; no tratamento com adição de $\mathrm{NO}_{3}^{-}$foi acelerada a evolução de $\mathrm{CO}_{2}$ resultante da decomposição da palha. Já no trabalho de I.EUKEN et alii (1962), a adição de $\mathrm{NH}_{4} \mathrm{NO}_{3}$ diminuiu a taxa de clecomposição do solo dos seguintes resíduos, medida pela evolução de $\mathrm{CO}_{2}$ : palha de trigo $(\mathrm{C} / \mathrm{N}=59,8 ; 0,787 \%$ de $\mathrm{N})$, alfafa $\quad(\mathrm{C} / \mathrm{N}=19,0$; $2,378 \%$ de $N)$ e glicose $(40 \%$ de $C$ e $0 \%$ die $N)$. No tratamento com celulose ( $41 \%$ de $\mathrm{C}$ e $0 \%$ de $\mathrm{N}$ ) o nitrogênio adicionado aumentou a taxa de evolução de $\mathrm{CO}_{2}$.

O aumento na taxa de decomposição da matéria orgânica, isto é, o aumento da atividade microbiana, corresponde a um acréscimo na imobilização de nitrogênio quanto o mesmo é aplicado ao solo (MUNDRA et alii, 1973). MUNDRA et alii (1973) observaram imobilização de nitrogênio até os 90 dias depois da aplicação de esterco $(C / N=36,9)$; depois desse período, houve acúmulo de $\mathrm{N}$ mineral nas amostras com este $\underline{r}$ co + fertilizante nitrogenado, possivelmente devido ao estre $\underline{i}$ tamento da relação $\mathrm{C} / \mathrm{N}$.

O nitrogênio liberado ou imobilizado vai se re fletir no crescimento das plantas. GANRY et alii (1978) constata ram que a incorporação de palha (a 0; 7,5 e 30 t/ha) diminuiu a produção de grãos e de matéria seca de painço, atribuindo es se fato à imobilização do nitrogênio. A aplicação de palha também resultou em depressões na produção de matéria seca e 
absorção de $\mathrm{N}$ por plantas de Lolium multiflorum, no trabalho de SCHERER e MENGEL (1981), refletinco o teor de $\mathrm{NO}_{3}^{-}$no mesmo solo previamente incubaclo com diferentes quantidades de pa1ha. KANAMORI e YASUDA (1979) também pré-incubaram solo com diferentes materiais orgânicos por 0,45 e 90 dias, depois do quê cultivaram centeio por 18 dias nesses solos. No tratamen to com palha de arroz $(\mathrm{C} / \mathrm{N}=56)$, o $\mathrm{N}$ absorvido diminuiu até os tratamentos com 45 dias de pré-incubação, começando a aumentar aos 90 dias, fato para cuja explicação os autores lembram a remineralização do nitrogênio imobilizado. Para os ou tros materiais, diferentes restos de diversas madeiras com re lações $C / N$ de 76, 268 e 679, houve decréscimo na absorção de $\mathrm{N}$ aos 90 dias, possivelmente pela dificuldade no ataque desses materiais pelos microrganismos.

Existe uma inter-relação entre mineralização/ imobilização e perdas de nitrogênio solo por desnitrificação. CANRY et alii (1978) constataram que a inco rpo ração de palha aumentou as perdas de nitrogênio, principalmente por desnitrificą̧ão, enquanto que CRASWELL (1978) observou o contrário, isto é, a diminuição da desnitxificação em presença de palha, justificando esse fato pela remoção de $\mathrm{NO}_{3}^{-}$através da imobilização. A imobilização de nitrogênio é menos acentuada em condições de anaerobiose (BROADBENT e NAKASHIMA, 1970), as quais favorecem a desnitrificação. BROADBENT e NAKASHIMA, 1970) verificaram que a taxa inicial de imobilização 
9.

foi maior nas amostras aerọ́bicas mas a imobilização continuou por maior periodo nas amostras incubadas anaerobicamente. Ex plicam esse fato, em parte, pela manutenção do $\mathrm{NH}_{4}^{+}$, a forma preferida pelos microrganismos do solo (MUNDRA et a $i$ i , 1973), num nível mais alto, enquanto que nos solos aerados o $\mathrm{NH}_{4}^{+}$é convertico mais rapidamente a $\mathrm{NO}_{3}^{-}$, que também é o substrato para a desnitrificação .

2.2. Efeito da Calagem sobre a Mineralização e a Imobilizą ção do Nitrogênio

JENSEN (1929) afirma que a concentraçã̃o hidrogeniônica do solo tem influência sobre a mineralização do nitrog̣ênio. A mirıeralização do próprio nitrogênio do solo é au mentada pela calagein, segundo NYBORG e HOYT (1978). Esses aú tores incubaram 40 solos diferentes, a $28^{\circ} \mathrm{C}$, com a umidade man tida próximo da capacidade de retenção de ågua. Os solos foram incubacbs em ausência ou presença de $\mathrm{Ca}(\mathrm{OH})_{2}+\mathrm{Mg}(\mathrm{OH})_{2}$ de maneira a elevar o valor do $\mathrm{pH}$ para 6,7. Observaram que, em mé dia, a calagem dobrou a quantidade de nitrogênio mineralizad, após 56 dias de incubação. EDMEADES et a $i$ ii (1981) também oḅ servaram aumento da mineralização de nitrogênio causado pela adição de: $\mathrm{CaCO}_{3}{ }^{\prime}$ Esses autores trabalharam com dois solos, com valores de $\mathrm{pH}$ iniciais de 5,3 e 5,1, utilizando tratamen 
tos com adição de $1,3,5$ e 10 te $\mathrm{CaCO}_{3}$ /ha ou sem a adição desse sal e plantando Lolium perenne em todos os tratamentos. Depois de oito semanas de incubação as plantas dos tratamentos sem $\mathrm{CaCO}_{3}$ apresentavamnitidos sintomas de deficiência de nitrogênio. Os autores explicaram a resposta observada na pró dução de matéria seca de Lolium perenne à calagem pelo aumen to na mineralização de nitrogênio.

2.3 - Efeito de Fatores do Ambiente sobre a Nitrificação

Além da imobilização, um outro destino do $\mathrm{NH}_{4}^{+}$ produzido na mineralização é a sua oxidação a $\mathrm{NO}_{3}^{-}$, a nitrifí cação, levada a efeito quase que exclusivamente por bactérias quimiolitotróficas. A passagem de $\mathrm{NH}_{4}^{+}$a $\mathrm{NO}_{2}^{-}$é feita por bactérias dos gêneros Nitrosomonas, Nitrosolobus e Nitrosospira, principalmente, e a passagem de $\mathrm{NO}_{2}^{-}$a $\mathrm{NO}_{3}^{-}$pelas co gênero Nitroluacler. Existem microrganismos quimiorganotróficos que realizam a nitrificaçäo (ISHAQUE e CORNFIELD, 1974), mas em escala bem menor. Há também alqumas menções “à nitrificação fotoquímica, isto é, a oxidação química do $\mathrm{NH}_{4}^{+}$a $\mathrm{NO}_{3}^{-}$catalisada pela luz, fenômeno de ocorrència bastante controvertida (DOMMERGUES e MANGENOT, 1970). Alguns autores (BARTHOLOMEW e CLARK, 1965; BUCKMAN e BRADY, 1967; LEES e OUASTEL, 1946). re ferem-se à existência de fotonitrificação em solos, dizendo apenas que, se esse fenômeno ocorrer, deve ser de pouca sig- 
nificância. VIRTANEN (1952) discute a origem dos óxidos de nitrogênio na atmosfera, comentando que somente uma pequena proporção do nitrito e do nitrato encontrados em precipitações pluviométricas é formada por descargas elétricas a partir de $\mathrm{N}$ molecular e que a fixação fotoquímica do $\mathrm{N}$ deve ser da maior importância para esse fenômeno. ERIKSSON (1952) cita que as quantidades de nitrato são maiores nos trópicos, a intensa radiação ultra-violeta liberando a energia de ativação necessária. O ozônio poderia ser o oxidante da molécula de amônio. ALLEN (1949) diz que sais de amônio, em solos tro picais, na presença de luz solar e de vários foto-sensibilizadores ou catalisadores $\left(\mathrm{TiO}_{2}, \mathrm{ZnO}, \mathrm{CdO}, \mathrm{Na}_{2} \mathrm{U}_{2} \mathrm{O}_{7}, \mathrm{Al}_{2} \mathrm{O}_{3}, \mathrm{MgO}\right)$, sofrem oxidação a $\mathrm{NO}_{2}^{-}$e $\mathrm{NO}_{3}^{-}$. Na ausência dos catalisadores a reação é muito menos pronunciada ou não ocorre.

A ñitrificação biológica tambëm sofre influên cia de diversos fatores ambientais: macronutrientes (ALEXAN DER, 1961), concentração de oxigênio (AMER e BARTHOLOMEW, 1951), temperatura (ANDERSON e BOSWELL, 1964), tensão osmótí Ca (JOHNSON e GUENZIE, 1963), micronutrientes (PREMI e CQRNFIELD, 1969), concentração de $\mathrm{NH}_{4}^{+}$e/ou $\mathrm{NO}_{3}^{-}$(ANDERSON e BOSWELI, 1964) e matéria orgânica (SCHERER e MENGEL, 1981), entre outros.

Todavia, dos fatores ambientais que exercem efeito sobre a nitrificação, o mais estudado parece ser acon centração hidrogeniônica do solo. A faixa de valores de pH 
em que ocorre a nitrificação é bastante ampla: Meek e Lipman (1922), citados por WEBER e GAINEY (1962), encontraram nitri ficadores ativos a valores de $\mathrm{pH} 4,1$ e 13; Gaasder e Hagem (1925), citados por WEBER e GAINEY (1962), situaram os valores mínimos de $\mathrm{pH}$ em que a nitrificação ocorre como estando entre 3,9 e 4,5. VENKATAKRISHNAN (1980) observou acúmulos de $\mathrm{NO}_{2}^{-}$e $\mathrm{NO}_{3}^{-}$em maior quantidade num solo com valor de $\mathrm{pH}=10,65$ que num outro com valor 8,3 .

De maneira gera], a nitrificação é majs inten sa em solos com valores de pH próximos da neutralidade (NYBORG e HOYT, 1978; WICKRAMASINGHË et alii, 1985). Já foi observada relação entre a prorcentagem de saturação em bases e em Ca e a nitrifjcação (NAFTEL, 1931), aumentando a intensidade da última com o aumento das duas primeiras. Em trabalho realizado por SANDANAM et aliii (1978), a adição do equivalen te a 2,8 $t$ de $\mathrm{CaCO}_{3}$ por hectare elevou o valor de $\mathrm{pH}$ de 4,0 para 5,2 e triplicou a nitrificação; com a aplicação do dobro de $\mathrm{CaCO}_{3}$, houve elevação do valor de $\mathrm{pH}$ para 6,0 e ainda se observou aumento da nitrificação. Num outro solo, conside rado "mais pobre" pelos autores, a primeira dose de $\mathrm{CaCO}_{3}$ ele vou o valor de $\mathrm{pH}$ para 6,0, havendo ligeiro aumento na inten sidade da nitrificação; com a segunàa dose, o valor de pH foi para 6,5, resultando em ligeira depressão da nitrificação.os autores concluíram que não é apenas a concentração hidroge- 
niônica do solo que determina a taxa de nitrificação nos solos ácidos. A conclusão semelhante chegaram WEBER e GAINEY (1962): a adição de $0,05 \%$ de $\mathrm{CaCO}_{3}$, que não alterou significativamente o valor de $\mathrm{pH}$ do solo (foi de 4,8 para 5,0, estą bilizando-se novamente em 4,8$)$ aumentou o acúmulo de $\mathrm{NO}_{3}^{-}$em $63 \%$ Esse fato sugere que a redução da concentração de $\mathrm{H}^{+}$pe la aplicação de $\mathrm{CaCO}_{3}$ não explica totalmente o efeito benéfí co do $\mathrm{CaCO}_{3}$ sobre a nitrificação. Somente $\circ \mathrm{Ca}^{++}$também não é significativamente efetivo, uma vez que $\mathrm{Ca}^{++}$aplicado como $\mathrm{CaSO}_{4}$ ou $\mathrm{CaHPO}_{4}$ em quantidade equivalente não resultou em au mento de $\mathrm{NO}_{3}^{-}$.

Fertilizantes nitrogenados também têm efeito. sobre a nitrificação, sendo que o equivalente a 1 t de $\left(\mathrm{NH}_{4}\right)_{2} \mathrm{SO}_{4}$ por hectare foi encontrado como retardando ou inibindo completamente a nitrificação (WEBER e GAINEY, 1962). BROADBENT et alii (1957) constataram inibição da nitrificação em solos inicialmente ácidos (valores de $\mathrm{pH}: 5,4,5,6$ e 6,4) quando se adicionaram $800 \mathrm{ppm}$ de $\mathrm{NH}_{4}^{+}$. Num solo com o valor inicial de $\mathrm{pH}$ igual a 7,4, a mesma quantidade de $\mathrm{NH}_{4}^{+}$também in $\underline{\mathbf{i}}$ biu a nitrificação. Em.solos inicialmente alcalinos (valores de $\mathrm{pH}: 7,6,8,0$ e 8,1$)$ houve acúmulo de $\mathrm{No}_{2}^{-}$, que depois desapareceu com correspondentes aumentos nos conteúdos de $\mathrm{NO}_{3}^{-}$. Esse acúmulo de $\mathrm{NO}_{2}^{-}$foi explicado como inibição das bac térias do gênero Nitrobacter pelo $\mathrm{NH}_{4}^{+}$. 
Há algumas explicações para inibição da nitrí ficação depois da aplicação de fertilizantes amoniacais (BROAD BENT et alii, 1957):

1) Valor de pH muito alto devido à aplicação de materiais alcalinos; todavia não se conhece um valor máximo de pH que limite a ocorrência da nitrificação.

2) Valor de pH muito baixo devido à formação de ácidos nitrico e nitroso. Solo próximo do local onde se apli cou fertilizante pode ficar muito ácido, como resultado até da própria nitrificação, sem que o resto do solo seja tão profundamente afetado.

3) Presença de $\mathrm{NH}_{4}^{+}$livre inibindo Nitrobacter, acumulan do-se $\mathrm{NO}_{2}^{-}$. Condições açudas poderiam inibir a transformação do $\mathrm{NH}_{4}^{+}$a $\mathrm{NO}_{2}^{-}$.

4) Efeito de sais, resultando em concentrações altas demais para atividade ótima das bactérias nitrificadoras.

2.4 - Efeito de Fatores do Ambiente sobre a Microflora atuante na Mineralização do Nitrogênio e Nitrifica ção

Os processos de mineralização/imobilização de nitrogênio e nitrificação, em sua maior parte, refletem as 
alterações sofridas pelas populações microbianas por eles res ponsáveis. A mineralização ocorre nas mais vạiadas condições, pela diversidade da microflora que nela atua. As bacté rias geralmente liberam menos amônio que os fungos, uma vez que o protoplasto das primeiras tem uma relação $\mathrm{C} / \mathrm{N}$ menor que o dos últimos $(4,5$ e 37,3 , respectivamente, segundo VAN VEEN e PAUL, 1979). Em presença de $\mathrm{NH}_{4}^{+}$e $\mathrm{NO}_{3}^{-}$, os microrganismos utilizam preferencialmente o primeiro (BROADBENT e NAKASHIMA, 1970; MUNDRA et alii, 1973). Pode haver fases "lag" na ativi dade das populações dos microrganismos responsáveis por amoni ficação e nitrificação, principalmente em solos sub-superficiais, onde a sua população é menor. Essas fases podem influenciar a taxa de mineralização de nitrogênio (STANFORD et alii, 1974).

Dada a diversidade da microflora atuante na mineralização, este fenômeno não é tão afetado por certas variações nas condições ambientais. Assim, EDMEADES et alii (1981) constataram que a calagem (aplicação de 0, 1, 3, 5 e 10 toneladas de $\mathrm{CaCO}_{3}$ por hectare) não exerceu efeito sobre as populações de bactérias aeróbicas e proteolíticas e fungos. SARATHCHANDRA (1978) observou que, independentemente dos valores de $\mathrm{pH}$, as populações de bactérias amonificadoras decuplicaram em uma semana de incubação. Todavia, com valores de $\mathrm{pH}$ de 5,5 , os números desses microrganismos eram da ordem de $10^{3} / \mathrm{g}$ de solo, enquanto que com valores de $\mathrm{pH}$ de 7,5 , da 
ordem de $10^{4} / \mathrm{g}$ de solo.

Os nitrificadores quimiolitotróficos, um grupo mais restrito de organismos, parecem estar mais dependentes das condições ambientais. No trabalho de SARATHCHANDRA (1978), quando se alteraram os valores de $\mathrm{pH}$ de 7,5 para 5,5, a população de oxidadores de $\mathrm{NH}_{4}^{+}$diminuiu de 12 a 14 vezes e a de oxidadores de $\mathrm{NO}_{2}^{-}$, de 5 a 7 vezes. EDMEADES et a $i$ i (1981) observaram aumento nas populações de nitrificadores, de maneira geral, com o aumento nas doses de $\mathrm{CaCO}_{3}$ aplicadas. A adição de fertilitiantess exerceu influência na população de nitrificadores en! solos sob floresta de Pinus, segundo MARTIKAINEN (1985). Os fertilizantes haviam sido aplicados dois anos antes das amostragens feitas. No tratamento sem fertilizantes a contagem de nitrificadores pelo método do número mais provável (NMP) não indicou a presença de nenhum desses microrganismos. A aplicação de $\mathrm{NH}_{4} \mathrm{NO}_{3}$ resul tou em algum aumento, quando a população se apresentou na or dem de $10^{2} / \mathrm{g}$ de solo, em algumas amostragens. A uréia foi o que mais estimulou a população, que se manteve, aproximadamente, entre $10^{4}$ e $10^{5}$ microrganismos por grama de solo.

A adição de torta de filtro ao solo como complementação aos fertilizantes minerais foi recomendada pela COPERSuCAR (s.d.) para a cultura da cana, afirmando esse órgão que a adição de 5 t de matéria seca de torta fornece, em 
mëdia, $70 \mathrm{~kg}$ de $\mathrm{N}, 97 \mathrm{~kg}$ de $\mathrm{P}_{2} \mathrm{O}_{5}$ e $20 \mathrm{~kg}$ de $\mathrm{K}_{2} \mathrm{O}$ por hectare. Todavia, sua relação C/N próxima da crítica $(26,4)$ em que ocorre imobilização de nitrogênio faz esperar que nem todo o nitrogênio contido na torta sejá liberado ao solo e tornado disponível às plantas, podenão ser necessária, para a sua de composição, a adição de fertilizantes nitrogenados. Uma vez que a decomposição da torta, levando à mineralização/imobili zação de nitrogênio, está diretamente ligada à atividade microbiológica, o conhecimento da variação da população microbiana ligada a esses fenômenos torna-se interessante. Isso está de acordo com o que diz MARTIKAINEN (1985), para quem os efeitos do manejo de florestas sobre a nitrificação são melhor indicados pela contagem de nitrificadores que por in cubação de solo, particularmente em solos imobilizando nitro gênio ativamente. Nesse trabalho, o autor usou o método do NMP, de largo emprego em microbiologia do solo, que, apesar de ser pouco preciso (ALEXANDER, 1965), é prático por não exigir equipamento sofisticado 。 
18.

\section{METODOLOGIA}

3.1 - Teste da Metodologia para Quantificação ćbs Microrga nismos Nitrificadores no Solo

Usou-se o método do número mais provável (NMP), que tem suporte estatistico no trabalho de HALVORSON e ZIEGJER (1932) e que se baseia na diluição à extinçăo.

O meio de cultura foi o indicado por PRAMER e SCHMIDT (1.964), cuja composição seque abaixo:

$$
\begin{aligned}
& \left(\mathrm{NH}_{4}\right)_{2} \mathrm{SO}_{4} \quad \ldots \ldots \ldots \ldots \ldots \quad 0,5 \mathrm{~g} \\
& \mathrm{Na}_{2} \mathrm{HPO}_{4} \quad \ldots \ldots \ldots \ldots \ldots, 13,5 \mathrm{~g}
\end{aligned}
$$

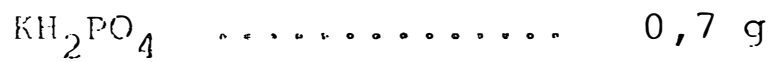

$$
\begin{aligned}
& \mathrm{MgSO}_{4} \cdot 7 \mathrm{H}_{2} \mathrm{O} \quad \ldots \ldots \ldots \ldots 0,0,1 \mathrm{~g} \\
& \mathrm{NaHCO}_{3} \quad \ldots \ldots \ldots \ldots \ldots . . \ldots 0,0,5 \mathrm{~g} \\
& \mathrm{FeCl}_{3} \cdot 6 \mathrm{H}_{2} \mathrm{O} \ldots \ldots \ldots \ldots, 0,014 \mathrm{~g} \\
& \mathrm{CaCl}_{2} \cdot 2 \mathrm{H}_{2} \mathrm{O} \quad \ldots \ldots \ldots \ldots \quad 0,018 \mathrm{~g} \\
& \mathrm{H}_{2} \mathrm{O} \text { destilada } \ldots \ldots \ldots \quad 1.000 \mathrm{ml}
\end{aligned}
$$


Antes da instalaçăo dos experimentos propriamente ditos, foram feitos testes de metodologia para a quantificação dos nitrificadores. Utilizou-se para os testes o mesmo solo a ser usado nos experimentos. Fizeram-se diluições de solo de $10^{-l}$ a $10^{-5}$, transferindo-se $1 \mathrm{ml}$ de cada diluição para 10 tubos de ensaio com o meio indicado, incubando-se metade dos tubos em condições de laboratório e metạ de em incubadora a $28^{\circ} \mathrm{C}$, sem agitação .

o período de inbucação foi de 10 semanas, de acordo com SCHMIDT e BELSER (1982), que recomendam incubação de pelo menos 6 semanas e avaliações da presença de $\mathrm{NH}_{4}^{+}$, $\mathrm{NO}_{2}^{-}$e $\mathrm{NO}_{3}^{-}$semanalmente até que não haja mudança no nümero de tubos de ensaio com reação positiva para esses íons por duas semanas consecutivas. A presença de $\mathrm{NH}_{4}^{+}$foi avaliada pelo reagente de Nessler e a de $\mathrm{NO}_{2}^{-} \in \mathrm{NO}_{3}^{-}$, pelo reagente de Griess 。

O reagente de Nessler tem a seguinte composiÇão (PRAMER e SCHIMDT, 1964):

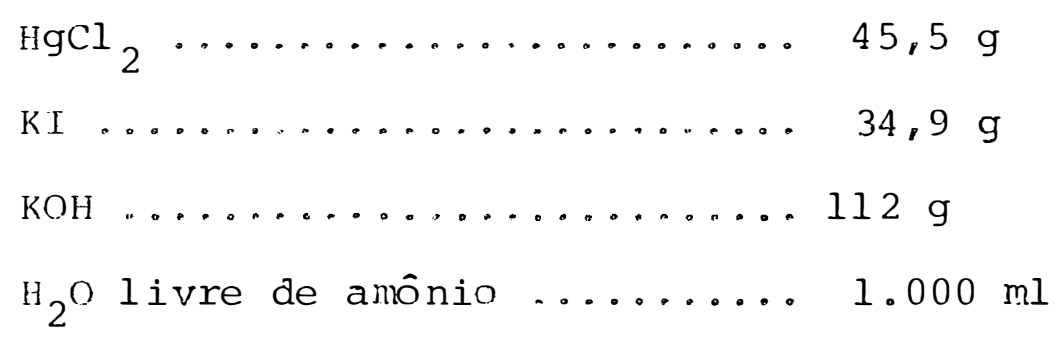

Para a análise da presença de $\mathrm{NH}_{4}^{+}$" juntam-se. em uma placa de toque (placa de porcelana com escavações), 2 gotas do reagente de Nessler e 3 gotas de solução a ser tes- 
tada. A presença de amônio é evidenciada pelo surgimento de uma cor alaranjada.

o reagente de Griess tem a seguinte composição (PRAMER e SCHMIDT, 1964):

Solução A:

- Ácido sulfanilico .......... 5 g

- Ácido acético (30\%) ........ $500 \mathrm{ml}$

Solução B:

- Alfa-naftilamina .......... 1,5 g

- $\mathrm{H}_{2} \mathrm{O}$ destilada $\ldots . . . . . . . . .350 \mathrm{ml}$

- Ácido acético glacial ....... 150 ml

As duas soluções são guardadas separadamente e, no momento do uso, são colocadas 3 gotas de cada uma em uma escavação da placa de toque juntamente com $0,5 \mathrm{ml}$ da solução que se deseja testar. O desenvolvimento de coloração avermelhada indica a presença de $\mathrm{NO}_{2}^{-}$. 
3 .2. Efeito da Torta de Filtro e do $\mathrm{CaCO}_{3}$ sobre a Mineralização e a Imobilização do Nitrogênio do Solo e sobre a Nitrificação

O solo utilizado para este experimento é um Latossolo Vermelho Escuro, da Estação Experimental de Limeira, do Instituto Agronômico, cuja anālise química apresentou os seguintes resultados, fornecidos pela Seção de Fertilidade do Solo e Nutrição de Plantas, do Instituto Agronômico: P (resina): $5 \mathrm{\mu g} / \mathrm{cm}^{3} ; \mathrm{M} .0 .: 3,1 \% ; \mathrm{pH}(\mathrm{em} \mathrm{CaCl} 2) ; 3,8 ; \mathrm{K}: 0,40$ $\mathrm{meq} / 100 \mathrm{~cm}^{3} ; \mathrm{Ca}: 0,3 \mathrm{meq} / 100 \mathrm{~cm}^{3} ; \mathrm{Mg}: 0,2 \mathrm{meq} / 100 \mathrm{~cm}^{3} ; \mathrm{H}+$ $\mathrm{Al}: 7,5 \mathrm{meq} / 100 \mathrm{~cm}^{3} ; \mathrm{S}: 0,9 \mathrm{meq} / 100 \mathrm{~cm}^{3} ; \mathrm{T}: 8,4 \mathrm{meq} / 100 \mathrm{~cm}^{3}$; $V: 11 \%$

Amostra de solo seca ao ar, destorroada e peneirada em peneira de 2 mu de malha foi incubada em copos plásticos. Os copos, com $400 \mathrm{~g}$ de terra, foram mantidos, sem plantas, em casa de vegetação da Seção de Microbiologia do Solo, do Instituto Agronômico.

Foram feitos os seguintes tratamentos:

1. Sem torta, sem $\mathrm{CaCO}_{3}$;

2. Sem torta, $\operatorname{com~} \mathrm{CaCO}_{3}$;

3. Com torta, sem $\mathrm{CaCO}_{3}$;

4. Com torta, $\operatorname{com} \mathrm{CaCO}_{3}$.

Foram feitas 3 repetições de cada tratamento. Cada parcela era constituída de 6 copos plásticos, corresponden 
tes às 6 épocas de amostragem $(0,10,30,50,70$ e 90 dias de incubação). Em cada época de amostragem, 3 copos de cada tratamento eram sorteaclos e submetidos às análises químicas e microbiológicas.

Com o fito de se observar o efeito da torta na imobilização do nitrogênio, adicionou-se torta de filtro em quantidade equivalente a 40 t de torta seca/ha, no momento da instalação dos experimentos. A torta de filtro, obtida na Usina Ester, em Cosmópolis, apresentou a seguinte análise química: $\mathrm{C}: 37 \% ; \mathrm{N}: 1,4 \% ; \mathrm{Ca}^{++}: 8.973 \mathrm{ppm} ; \mathrm{Mg}^{++}: 2.263$ ppm; K: $4.340 \mathrm{ppm} ; \mathrm{Na}^{+}: 110 \mathrm{ppm} ; \mathrm{Zn}: 89 \mathrm{ppm} ; \mathrm{Cu}: 45 \mathrm{ppm} ; \mathrm{Fe}$ : $13.612 \mathrm{ppm} ; \mathrm{Mn}: 3.514 \mathrm{ppm} ; \mathrm{P}: 278 \mathrm{ppm}$. A anälise foi feita pela Seção de Pedologia do Instituto Agronômico. Depois de seca ao ar, a torta foi moída e passada em peneira com malha de $1 \mathrm{~mm}$.

Com a adição de $\mathrm{CaCO}_{3}$ desejava-se elevar o va lor de pH para 6,5 (em água). O cálculo da quantidade de $\mathrm{CaCO}_{3}$ foi efetuado pelo método em uso no Instituto Agronômico , pela fórmula:

$$
\mathrm{NC}=\frac{T\left(V_{2}-V_{1}\right)}{100}
$$

em que:

NC: necessidade de calagem;

$T$ : capacidade de troca de cátions; 
$\mathrm{V}_{2}$ : saturação em bases desejada;

$\mathrm{V}_{1}$ : saturação em bases fornecida pela anālise.

$$
\text { Pra o cálculo de } V_{2} \text { utiliızou-se a equação de }
$$

regressão:

$$
\mathrm{pH}=4,45+0,021 \mathrm{~V} \%
$$

obtendo-se um valor $\mathrm{V}_{2}=98 \%$ para o valor de $\mathrm{pH}$ desejado de 6,5 .

Dessa forma, concluiu-se que havia necessidade de se adicionarem 7,2 meq de $\mathrm{CaCO}_{3} / 100 \mathrm{~cm}^{3}$ de solo.

Depois da adição do $\mathrm{CaCO}_{3}$ o solo foi irrigado com āgua destilada até $60 \%$ da capacidade de retençăo de água, umidade que foi mantida por pesagem. Periodicamente foram feitas medições dos valores de pH até que o solo atingisse o valor desejado, cerca de um mês depois. Feito isto, permitiu-se que o solo secasse nos copos, por um mês, para facilitar o seu manuseio quando da adição de torta.

$$
\text { Aos } 0,10,30,50,70 \text { e } 90 \text { dias de incubação }
$$
o solo foi submetido à determinaçăo dos números mais provăveis de microrganismos amonificadores e nitrificadores.

Para os microrganismos amonificadores, foi usado o meio de cultura indicado por POCHON e TARDIEUX (1972), com a seguinte composição: 
- Soluçào salina $(0,85 \%$ de $\mathrm{NaCl}) \ldots . . . .50 .50 \mathrm{ml}$

- Asparagina .................. 0, 2 g

- Agua destilada ............... q.s.p. $1.000 \mathrm{ml}$

Fizeram-se diluições de solo de $10^{-3}$ a $10^{-7}$ (aos 0 e 10 dias de incubação) e de $10^{-6}$ a $10^{-10}$ (aos 30, 50, 70 e 90 dias de incubação). Transferiu-se $1 \mathrm{ml}$ de cada diluição a 5 tubos de ensaio com o meio de cultura indicado. Os tubos foram mantidos em incubadora a $28^{\circ} \mathrm{C}$ por 2 semanas, quando então se procedeu à avaliação da presença de $\mathrm{NH}_{4}^{+}$com o reagente de Nessler. A partir do número de tubos com reação positiva para $\mathrm{NII}_{4}^{+}$, obtiveram-se os números mais prováveis de microrganismos utilizando-se a tabela apresentada por ALEXANDER (1982).

Para os microrganismos nitrificadores, o meio de cultura usado foi o mesmo já descrito no item 3.1. Utili zaram-se as diluições de solo de $10^{-1}$ a $10^{-5}$, incubando-se os tubos em incubadora a $28^{\circ} \mathrm{C}$, por 8 semanas, após o quê pro cedeu-se à avaliação da presença de $\mathrm{NO}_{2}^{-}$e $\mathrm{NO}_{3}^{-}$, com o reagente de Griess.

Ao final de cada época de incubação, o solo era submetido a anälises de $\mathrm{N}_{-} \mathrm{NH}_{4}^{+}$e $\mathrm{N}-\mathrm{NO}_{3}^{-}$' pelo método de BREMNER (1965)。 
3.3 - Efeito da Torta de Filtro e do $\mathrm{CaCO}_{3}$ sobre a Minera lização e a Imobilização do Nitrogênio do Solo e so bre a Nitrificação, em Presença de Nitrogênio AdiCiona do

Este experimento utilizou os mesmos métodos, os mesmos materiais e os mesmos tratamentos que os descritos no item 3.2. A única diferença reside no fato de que adicionou-se nitrogênio a toảos os tratamentos, com o objetivo ảe observar-se a mineralização e a imobilização do nitrogênio em solo com relação $\mathrm{C} / \mathrm{N}$ de cerca de 15 e, portanto, abai xo da apontada como crítica (20) na literatura. O nitrogênio foi aplicacio na forma de solução de $\mathrm{NH}_{4} \mathrm{NO}_{3}$ ' esterilizada, lo ml por copo, resultando que a cada copo com $400 \mathrm{~g}$ de solo foi adicionado $0,184 \mathrm{~g}$ de $\mathrm{NH}_{4} \mathrm{NO}_{3}$, com concentração final de 161 ppm de $N$ no solo.

\section{4 - Delineamento Experimental e Análises Estatísticas}

Nos dois experimentos descritos nos itens 3.2 e 3.3, o delineamento experimental foi inteiramente casualizado e a análise estatística seguiu o esquema de parcelas subdivididas. Quanto a interação tratamentos $\mathrm{x}$ épocas foi significativa, fez-se desdobramento, analisando-se tratamentos dentro de época.

Foi utilizado o teste F. 
4.1. Teste da Metodologia para Quantificação dos Microrganismos Nitrificadores no solo

No ensaio realizado para verificação da metodologia, observou-se, da $2^{a}$. semana de incubação em diante, a presença de $\mathrm{NO}_{2}^{-}$nos tubos-controle, sob luz, que continham méio esterilizado e que deveriam, teoricamente, ter reação positiva apenas para amônio. Os resultados dessas avaliações, apenas para os tubos-controle, econtram-se na Tabela 1 , apenas para as quatro primeiras semanas de incubação. Os re sultados foram os mesmos para as avaliações seguintes. 
Tabela 1 - Presença de $\mathrm{NH}_{4}^{+}, \mathrm{NO}_{2}^{-}$e $\mathrm{NO}_{3}^{-}$, em 4 períodos de inbu bação, no escuro e sob luz, em meio completo para nitrificadores.

\begin{tabular}{|c|c|c|c|c|c|c|c|c|}
\hline & \multicolumn{2}{|c|}{1 SEMANA } & \multicolumn{2}{|c|}{2 SEMANAS } & \multicolumn{2}{|c|}{3 SEMANAS } & \multicolumn{2}{|c|}{4 SEMANAS } \\
\hline & escuro & luz & escuro & luz & escuro & luz & escurro & luz \\
\hline $\mathrm{NH}_{4}^{+}$ & + & + & + & + & + & + & + & + \\
\hline $\mathrm{NO}_{2}^{-}$ & - & - & - & + & - & + & - & + \\
\hline $\mathrm{NO}_{3}^{-}$ & - & - & - & - & - & - & - & - \\
\hline
\end{tabular}

+: reação positiva; -: reação negativa.

A reação para a presença de $\mathrm{NO}_{2}^{-}$foi francamen te positiva apoós 2 semanas de incubação em condições de labo ratório e, portanto, sob luz, confirmando a hipótese de que a luz favorece, de maneira ainda indeterminada, uma reaçã̃o de oxidação química do $\mathrm{NH}_{4}^{+}$. Não se detectou $\mathrm{NO}_{3}^{-}$durante o perỉodo de incubação do teste, não se sabe se porque esse ion não foi produzido ou porque as quantidades eventualmente pro duzidas não foram suficientemente grandes para serem detecta das pelo reagente de Griess.

Em virtude desses resultados, aventou-se a hi pótese da ocorrência de nitrificação fotoquímica, apesar de não se ter encontrado, na literatura, nenhuma constatação des se fenômeno em meios de cultura. Todavia, como ALLEN (1949) menciona claramente a existência de fotonitrificação em so- 
los, inclusive citando alguns catalisadores, fez-se novo tes te, usando-se $\left(\mathrm{NH}_{4}\right)_{2} \mathrm{SO}_{4}$ mais cada um dos componentes do meio em separado, de maneira a detectar um possível efeito de catalisação. Os resultados obtidos nas 26 semanas de incubação são apresentados, resumidamente, na Tabela 2. Somente são in dicadas as reações para $\mathrm{NO}_{2}^{-}$, uma vez que $\mathrm{NO}_{3}^{-}$nunca foi detec tado. Como os resultados tenderam a se manter por algum tempo, são apresentados apenas os das avaliações em que se observaram mudanças. Após a 5 å semana de incubação todos os tra tamentos, com exceção do que continha $\left(\mathrm{NH}_{4}\right)_{2} \mathrm{SO}_{4}+\mathrm{FeCl}_{3} \cdot 6 \mathrm{H}_{2} \mathrm{O}$, apre sentaram reação francamente positiva para $\mathrm{NO}_{2}^{-}$nos frascos in cubados sob luz. Na 10å semana, também o tratamento com $\mathrm{FeCl}_{3} \cdot 6 \mathrm{H}_{2} \mathrm{O}$ apresentou reação francamente positiva. para $\mathrm{NO}_{2}^{-}$. O tratamento que continha apenas $\left(\mathrm{NH}_{4}\right)_{2} \mathrm{SO}_{4}$ apresentou oxidação química do $\mathrm{NH}_{4}^{+}$influenciada pela luz, detectada após a 5ạ semana, assim como os tratamentos com $\left(\mathrm{NH}_{4}\right)_{2} \mathrm{SO}_{4}+\mathrm{MgSO}_{4} \cdot 7 \mathrm{H}_{2} \mathrm{O}$, $\left(\mathrm{NH}_{4}\right)_{2} \mathrm{SO}_{4}+\mathrm{NaHCO}_{3}$ e $\left(\mathrm{NH}_{4}\right)_{2} \mathrm{SO}_{4}+\mathrm{CaCl}_{2} \cdot 2 \mathrm{H}_{2} \mathrm{O}$. Os componentes do meio nos três últimos tratamentos acima citados parecem não ter influência sobre o processo, uma vez que tiveram o mesmo comportamento que o tratamento apenas com $\left(\mathrm{NH}_{4}\right)_{2} \mathrm{SO}_{4}$. Já os tratamentos com $\left(\mathrm{NH}_{4}\right)_{2} \mathrm{SO}_{4}+\mathrm{Na}_{2} \mathrm{HPO}_{4}$ e $\left(\mathrm{NH}_{4}\right)_{2} \mathrm{SO}_{4}+\mathrm{KH}_{2} \mathrm{PO}_{4}$ apresentaram reação positiva para $\mathrm{NO}_{2}^{-}$na 2 ă e 4 ạ semanas, respectivamente, parecendo acelerar o processo. Após a 18a semana de incuba- 
ção, no tratamento com $\left(\mathrm{NH}_{4}\right)_{2} \mathrm{SO}_{4}+\mathrm{Na}_{2} \mathrm{HPO}_{4}$ houve uma reação fracamente positiva para $\mathrm{NO}_{2}^{-}$em ausência de luz. Esse mesmo tratamento é o que acusou, antes dos outros, presença de $\mathrm{NO}_{2}^{-}$ quando incubado sob luz. Pode-se aventar a hipótese de que no $\mathrm{Na}_{2} \mathrm{HPO}_{4}$ haja um catalisador da reação química de oxidação do amônio, seja esse catalisadox o próprio sal ou alguma impureza nele contida.

Tabela 2 - Efeito de diferentes ompostos do meio de cultura para nitrificadores sobre a fotonitrificação. (Reação ao Griess para presença de $\mathrm{NO}_{2}$ )

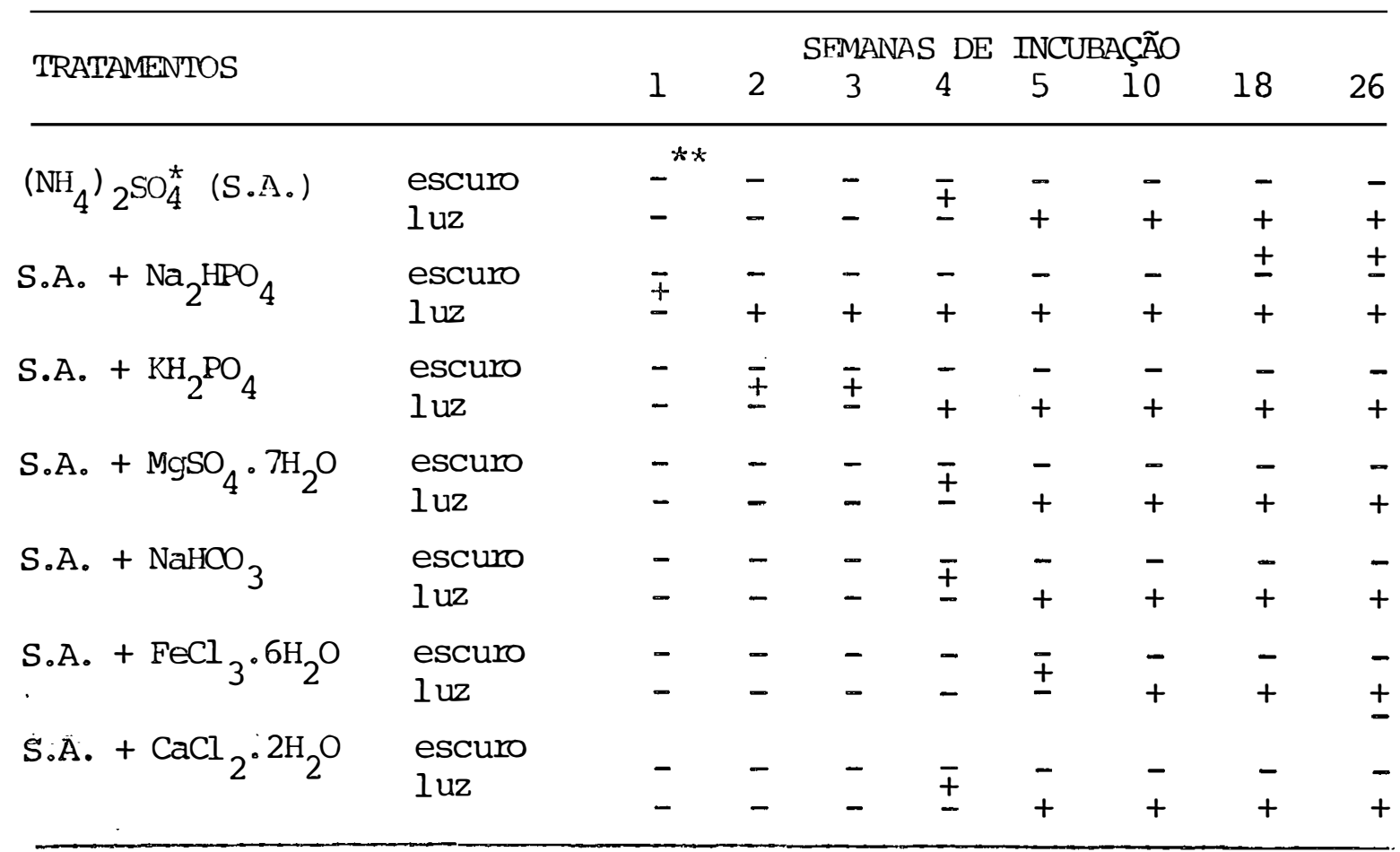

* Concentrações dos sais nos diferentes tratamentos: $\left(\mathrm{NH}_{4}\right)_{2} \mathrm{SO}_{4}: 0,5 \mathrm{~g} / 1$ (presente em toüos os tratamentos) : $\mathrm{Na}_{2} \mathrm{HPO}_{4}: 13,5 \mathrm{~g} / 1 ;{ }^{4} \mathrm{KH}_{2} \mathrm{PO}_{4}: 0,7 \mathrm{~g} / \mathbf{l}_{\text {; }}$ $\mathrm{MgSO}_{4} \cdot 7 \mathrm{H}_{2} \mathrm{O}: 0,1 \mathrm{~g} / \mathrm{l} ; \mathrm{NaHCO}_{3}: 0,5 \mathrm{~g} / \mathrm{l} ; \mathrm{FeCl}_{3} \cdot 6 \mathrm{H}_{2} \mathrm{O}: 0,014 \mathrm{~g} / 1 ; \mathrm{CaCl}_{2}$. $2 \mathrm{H}_{2} \mathrm{O}: 0,018 \mathrm{~g} / \mathrm{l}$.

** +: reação positiva para $\mathrm{NO}_{2}^{-}$-: reação negativa para $\mathrm{NO}_{2}^{-} \pm$: reação fracamente positiva para $\mathrm{NO}_{2}^{\circ}$

S.A.: sulfato de amônio

Obs.: Os testes para presença de $\mathrm{NH}_{4}^{+}$, com o reagente de Nessler, foram sempre positivos, para tocbs ơs tratamentos. 
4.2 - Efeito da Torta de Filtro e do $\mathrm{CaCO}_{3}$ sobre a Minera lização e Imobilização do Nitrogênio do solo e sobre a Nitrificação

Os resultados para a estimativa dos números mais prováveis de microrganismos amonificadores estão na Tabela 3 e para os nitrificadores na Tabela 4 . Os resultados das análises de $\mathrm{N}_{-} \mathrm{NH}_{4}^{+}$estão na Tabela 5, para $\mathrm{N}-\mathrm{NO}_{3}^{-}$, na Tabela 6 e para $\mathrm{N}-\mathrm{NH}_{4}^{+}+\mathrm{N}-\mathrm{NO}_{3}^{-}$, na Tabela 7. As Figuras 1, 2 e 3 representam as variações nos teores de $\mathrm{N}_{-} \mathrm{NH}_{4}^{+}, \mathrm{N}^{-} \mathrm{NO}_{3}^{-}$e $\mathrm{N}-\mathrm{NH}_{4}^{+}+\mathrm{N}-\mathrm{NO}_{3}^{-}$, respectivamente. Os valores de $\mathrm{F}$ obtidos na análise estatística encontram-se nas Tabelas 13 a 15, do Apêndice.

Tabela 3 - Microrganismos amonificadores $\left(x 10^{5}\right)$ por grama de solo nas di ferentes épocas de amostragem (médias de 3 repetições) (10 ex perimento) .

\begin{tabular}{crrrr}
\hline \multirow{2}{*}{$\begin{array}{c}\text { DIAS } \\
\text { INCUBAÇÃO }\end{array}$} & T R A T A M N T O S* \\
\cline { 2 - 5 } & $1 . \mathrm{T}-\mathrm{C}-$ & $2 . \mathrm{T}-\mathrm{C}+$ & $3 . \mathrm{T}+\mathrm{C}-$ & $4 . \mathrm{T}+\mathrm{C}+$ \\
\hline 0 & 5,0 & 76,3 & 7,5 & $>180,0$ \\
10 & 180,0 & $>180,0$ & $>180,0$ & $>180,0$ \\
30 & 56,1 & 379,3 & 802,8 & 773,2 \\
50 & 96,2 & 618,0 & 491,1 & $1.074,3$ \\
70 & 63,7 & 72,9 & 160,3 & 107,1 \\
90 & 81,7 & 64,5 & 522,7 & $1.617,3$ \\
\hline
\end{tabular}

*T: torta de filtro; $\mathrm{C}: \mathrm{CaCO}_{3}$

+: presença; -: ausência. 
Tabela 4 - Mjcrorganismos nitrificadores por grama de solo para as diferentes épocas de amostragem (médias de 3 repetições) (1: experimento).

\begin{tabular}{ccccc}
\hline \multirow{2}{*}{$\begin{array}{c}\text { DIAS } \\
\text { INCUBACAO }\end{array}$} & T. T R A T $\mathrm{TM} \mathrm{N} \mathrm{N} \mathrm{T} \mathrm{O} \mathrm{S}$ \\
\cline { 2 - 5 } & 15,2 & $2 . \mathrm{T}-\mathrm{C}+$ & $3 . \mathrm{T}+\mathrm{C}-$ & $4 . \mathrm{T}+\mathrm{C}+$ \\
\hline 0 & 4,0 & 66,5 & 0,0 & 3,4 \\
10 & 10,9 & 8,6 & 1,4 & 4,7 \\
30 & 8,5 & 12,6 & 0,7 & 3,7 \\
50 & 4,1 & 19,5 & 2,6 & 26,5 \\
70 & 1,5 & 9,1 & 0,8 & $2.968,5$ \\
90 & 3,8 & 0,8 & 98,3 \\
\hline
\end{tabular}

*T: torta de filtro; $\mathrm{C}: \mathrm{CaCO}_{3}$

+: presença; -: ausência.

Tabela 5 - ${\mathrm{N}-\mathrm{NH}_{4}^{+}}_{4}(\mu \mathrm{g} / \mathrm{g}$ de solo) para as diferentes épocas de amostragem (médias de 3 repetições) (io experimento).

\begin{tabular}{ccccc}
\hline $\begin{array}{c}\text { DIAS } \\
\text { DE } \\
\text { INCURAÇAO }\end{array}$ & \multicolumn{4}{c}{ T R A T A M N T O S* } \\
\cline { 2 - 5 } & $1 . \mathrm{T}-\mathrm{C}-$ & $2 . \mathrm{T}-\mathrm{C}+$ & $3 . \mathrm{T}+\mathrm{C}-$ & $4 . \mathrm{T}+\mathrm{C}+$ \\
\hline 0 & 5,0 & 8,4 & 2,6 & 8,4 \\
10 & 4,1 & 12,5 & 0,2 & 0,0 \\
30 & 6,4 & 11,3 & 0,7 & 7,8 \\
50 & 5,7 & 15,5 & 1,7 & 4,4 \\
70 & 0,6 & 10,1 & 0,0 & 4,2 \\
90 & 0,5 & 9,4 & 0,0 & 3,2 \\
\hline
\end{tabular}

*T: torta de filtro; C: $\mathrm{CaCO}_{3}$

+: presença; -: ausência. 
Tabela $6-\mathrm{N}_{-} \mathrm{NO}_{3}^{-}(\mu \mathrm{g} / \mathrm{g}$ de solo) para as diferentes épocas de amostragem (médias de 3 repetiçōes) (1: experimento) .

\begin{tabular}{ccccc}
\hline $\begin{array}{c}\text { DIAS } \\
\text { DE } \\
\text { INCUBAÇÃO }\end{array}$ & T R A T A M E N T O S* \\
\cline { 2 - 5 } & $1 . \mathrm{T}-\mathrm{C}-$ & $2 . \mathrm{T}-\mathrm{C}+$ & $3 . \mathrm{T}+\mathrm{C}-$ & $4 . \mathrm{T}+\mathrm{C}+$ \\
\hline 0 & 4,5 & 3,3 & 3,0 & 1,0 \\
10 & 2,9 & $4, \varepsilon$ & 0,8 & 0,1 \\
30 & 5,8 & 5,8 & 0,4 & 1,6 \\
50 & 7,2 & 5,6 & 1,0 & 1,5 \\
70 & 7,1 & 4,9 & 0,1 & 1,7 \\
90 & 7,2 & 4,7 & 0,7 & 1,7 \\
\hline
\end{tabular}

*T: torta de filtro; $\mathrm{C}: \mathrm{CaCO}_{3}$

+: presença; -: ausênicia.

Tabela $7-\mathrm{N}-\mathrm{NH}_{4}^{+}+\mathrm{N}-\mathrm{NO}_{3}^{-}$( $\mu \mathrm{g} / \mathrm{g}$ de solo) para as diferentes épocas de amos tragem (médias de 3 repetições) (1: experimento) 。

\begin{tabular}{ccccc}
\hline \multirow{2}{*}{$\begin{array}{c}\text { DIAS } \\
\text { DE } \\
\text { INCUBAÇÃO }\end{array}$} & \multicolumn{4}{c}{ T R A T A M E N T O S* } \\
\cline { 2 - 5 } & $1 . \mathrm{T}-\mathrm{C}-$ & $2 . \mathrm{T}-\mathrm{C}+$ & $3 . \mathrm{T}+\mathrm{C}-$ & $4 . \mathrm{T}+\mathrm{C}+$ \\
\hline 0 & 9,5 & 11,7 & 5,5 & 9,4 \\
10 & 6,9 & 17,2 & 1,1 & 0,1 \\
30 & 12,2 & 17,0 & 1,1 & 9,4 \\
50 & 12,8 & 21,1 & 2,6 & 5,9 \\
70 & 7,8 & 15,1 & 0,1 & 5,9 \\
90 & 7,7 & 14,1 & 0,7 & 4,9 \\
\hline
\end{tabular}

*T: torta de filtro; $\mathrm{C}: \mathrm{CaCO}_{3}$

+: presença; -: ausência. 


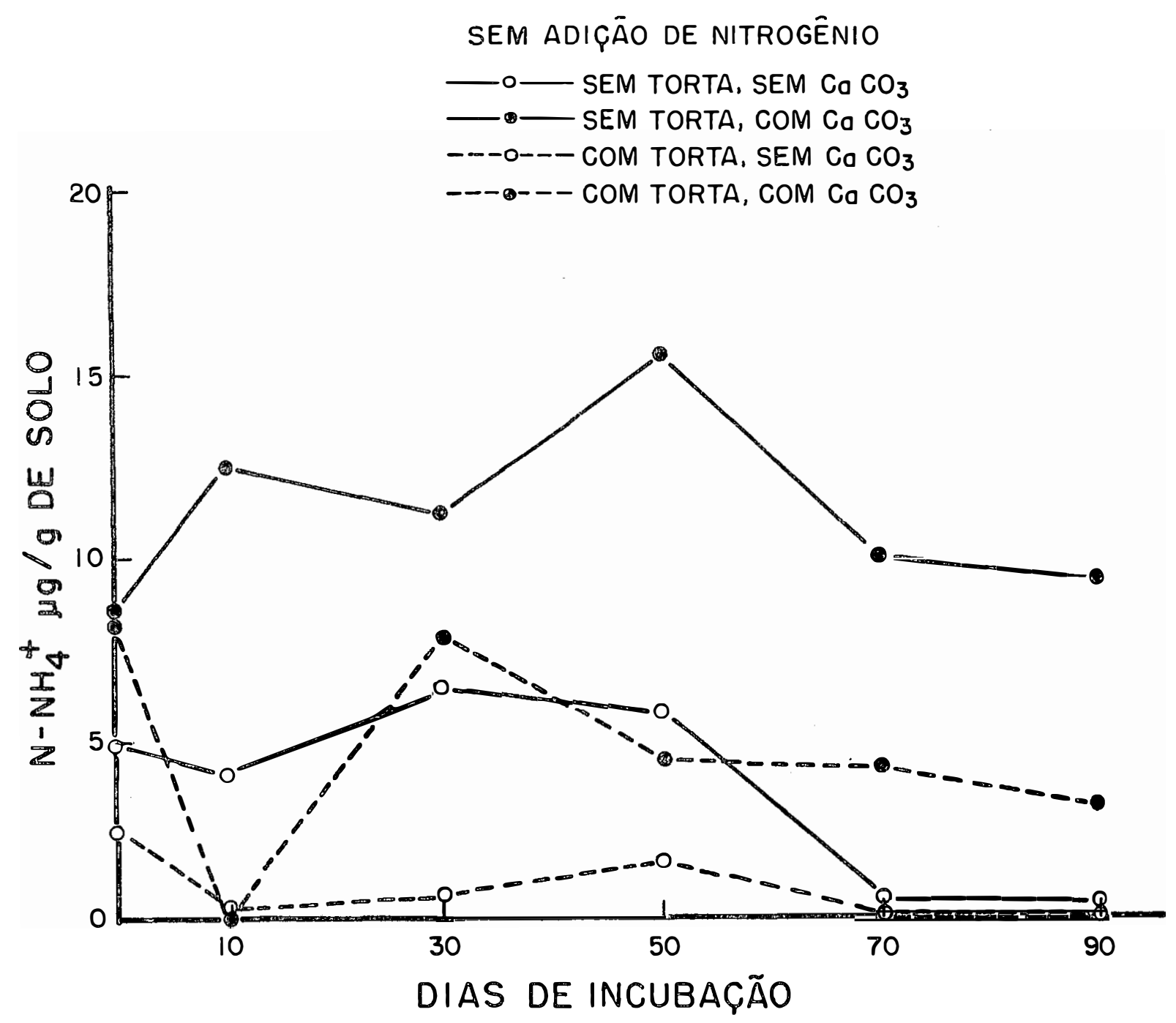

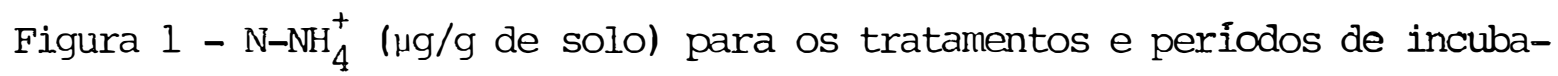
ção indicados (médias de 3 repetições) (1: experimento). 

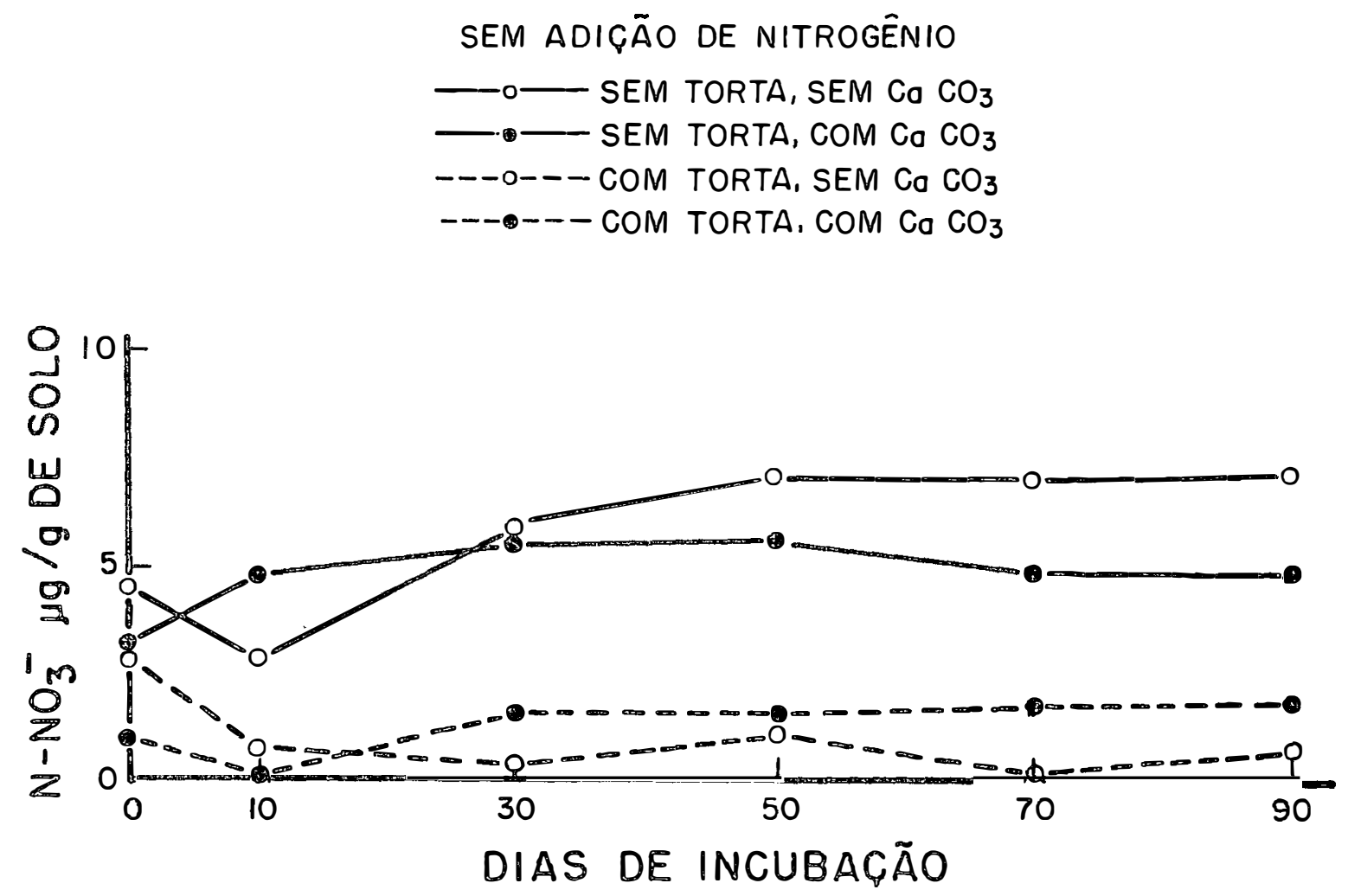

Figura 2 - ${\mathrm{N}-\mathrm{NO}_{3}^{-}}^{-}(\mathrm{\mu g} / \mathrm{g}$ de solo) para os tratamentos e periodos de incubação indicados (médias de 3 repetições) (10 experimento). 

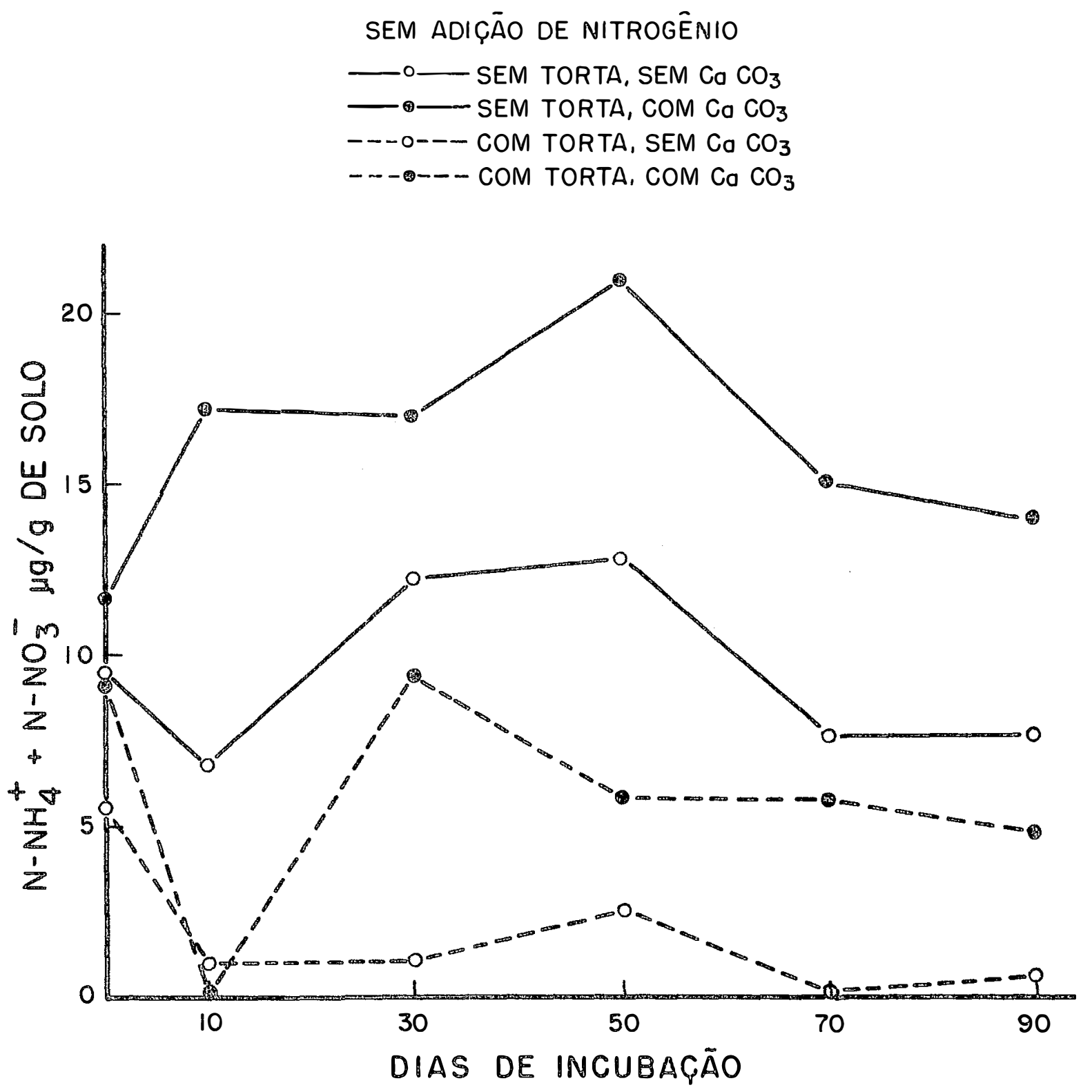

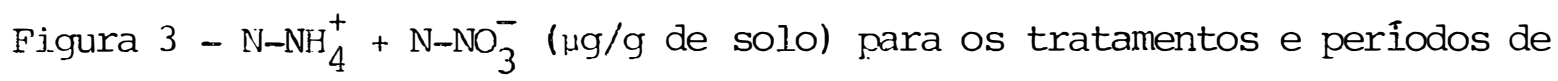
incubação indicados (médias de 3 repetições) (19 experimento) . 
Na primeira amostragem, no início do experimento, para o tratamento $\mathrm{T}+\mathrm{C}+$ e na amostragem aos 10 dias de incubaçäo, para todos os tratamentos, todos os tubos, feitos a partir de todas as djuluições de solo (de $10^{-3}$ a $10^{-7}$ ), apre sentaram reação positiva para a presença de $\mathrm{NH}_{4}^{+}$, não sendo possivel determinar O NMP de microrganismos amonificadores. Sabe--se apenas que esses números foram maiores que $180 \times 10^{\mathrm{b}}$. Para $\circ \mathrm{NH}_{4}^{+}$(Tabela 5 e Figura 1), logo na amos tragem feita quando da instalação do experimento, observa-se uma diferença altamente significativa entre os tratamentos com e sem $\mathrm{CaCO}_{3}$. A adição de $\mathrm{CaCO}_{3}$, feita dois meses antes, deve ter agido sobre a microfiora amonificadora, estimulando-a e ocasionando maior liberação de $\mathrm{NH}_{4}^{+}$. A análise estatís tica referente ao NMP de microrganismos amonificadores apresentou um coeficiente de variação muito alto, não se detectando diferenças significativas. Ainda assim, na Tabela 3 , po de-se observar uma tendência de aumento dessa população nos tratamentos com $\mathrm{CaCO}_{3}$. Esse aumento na população amonificado ra não está de acordo com EDMEADES et alii (1981), que não observaram efeito da adição de até $10 t$ de $\mathrm{CaCO}_{3}$ por hectare sobre as populações de bactérias anaeróbicas e proteolíticas e fungos, constatando, embora, aumento na mineralização de nitrogênio como efeito do $\mathrm{CaCO}_{3}$. Talvez a estimativa da popu lação amonificadora como um todo, como neste trabalho, seja 
mais eficiente em detectar suas variações que os métodos usa dos por EDMEADES et alii (1981), que estimaram grupos mais especificos de organismos, separadamente.

Já na segunda amostragem, aos dez dias de incubação, a adição de torta ocasionou drástica redução no teor de $\mathrm{N}-\mathrm{NH}_{4}^{+}$no solo. "A torta, $\infty \mathrm{m} 1,4 \%$ de $\mathrm{N}$ e estanco pouoo acima da faixa apontada por BARTHOLOMEW (1965) (1-1,3\% de N), realmente levou à imobilização de nitrogênio, rapidamente. $\mathrm{O}^{\mathrm{CaCO}_{3}}$ também manteve o efeito sobre a quantidade de $\mathrm{N}_{-} \mathrm{NH}_{4}^{+}$. Aliás, esse efeito do $\mathrm{CaCO}_{3}$, aumentando a quantidade de $\mathrm{N}-\mathrm{NH}_{4}^{+}$, foi altamente significativo em todas as amostragens. Isso pode ser devido a um efeito do $\mathrm{CaCO}_{3}$ sobre os microrganismos amonificadores, que teriam sido beneficiados com a elevação dos valores ảe pH em ăgua (füi, em média, de 4,1, nos tratamentos sem $\mathrm{CaCO}_{3}$, e de 6,7 nos tratamentos com $\left.\mathrm{CaCO}_{3}\right)$. Pode-se verificar esse efeito do $\mathrm{CaCO}_{3}$ sobre a população amonificadora na Tabela 3, onde se observa que o NMP dessa população foi maior em presença do sal em praticamente todas as amostragens. Ainda nessa amostragem, aos dez dias de incubação, foi altamente significativa a interação torta x $\mathrm{CaCO}_{3}$ : em ausência de torta, $\mathrm{O}^{\mathrm{CaCO}_{3}}$ estimulou a mineralização do nitrogênio, mas, em presença de torta, o $\mathrm{CaCO}_{3}$ levou o teor de $\mathrm{N}_{-} \mathrm{NH}_{4}^{+}$a zero. Isto é, a calagem estimulou a mineralização de nitrogênio, pelo estímulo à microflora amonificadora. Todavia, na qualidade de material orgânico, a torta estimula o 
crescimento da população microbiana como um todo (ALEXANDER, 1961). Assim, o aumento da população em geral teria sido suficiente para consumir todo o nitrogênio mineralizado, imobilizando-o. Ainda que aumentada a população amonificadora, com a conseqüente maior liberação de $\mathrm{N}^{-\mathrm{NH}_{4}^{+}}$no solo, a popula ção em geral teria imobilizado todo esse nitrogênio. Não se podem comparar esses dados referentes ao $\mathrm{N}_{-} \mathrm{NH}_{4}^{+}$no solo com o NMP de microrganismos amonificadores (Tabela 3), supondo-se apenas que o grande aumento nos números desses organismos aos dez dias de incubação seja devido ao reinício da irrigação dos vasos, quando da instalação do experimento.

A imobilização do $\mathrm{NH}_{4}^{+}$nos tratamentos com tor ta de filtro, detectada já aos dez dias de incubação, manteve-se nas amostragens subseqüentes, perdurando nos noventa dias que durou o experimento. Esse efeito da torta na imobilização do $\mathrm{N}^{-\mathrm{NH}_{4}^{+}}$pode ser comprovado pela análise da Tabela 3: O NMP de microrganismos amonificadores foi maior nos tratamentos com torta, em todas as amostragens, que nos sem tor ta. Se a microflora que atua na amonificação é bastante diversificada (ALEXANDER, 1961), incluindo variados grupos de microrganismos, é razoável supor-se que essa população reflí ta mudanças ocorridas na população microbiana geral do solo. Assim como os amonificadores foram estimulados pela torta também o deve ter sido toda a população de microrganismos qui 
miorganotróficos do solo, explicando-se dessa forma a imobilização de $\mathrm{N}-\mathrm{NH}_{4}^{+}$nos tratamentos com torta de filtro.

Depois dos cinqüenta dias de incubação houve queda no teor de $\mathrm{N}-\mathrm{NH}_{4}^{+}$em todos os tratamentos (Tabela 5, Fi gura 1). Podem ter ocorrido perdas de nitrogênio do sistema. Comparando-se as Figuras 1 e 2, nota-se que aos decréscimos nas quantidades de $\mathrm{N}_{-} \mathrm{NH}_{4}^{+}$a partir dos cinqüenta dias não hou ve acréscimos correspondentes nos teores de $\mathrm{N}_{-} \mathrm{NO}_{3}^{-}$. Para que o nitrogênio tenha sido perdido na forma amoniacal, pode-se aventar a hipótese dé volatilização de $\mathrm{NH}_{3}$. Mas o nitrogênio também poderia ter sido perdido a partir da forma nítrica, por desnitrificação, ainda que năo se espere a ocorrè̀ncia de condições anaeróbicas, em grandes extensões, nestas condi६ões. Nesse caso, teria ocon rrido nitrificação, mas o $\mathrm{NO}_{3}^{-}$ resultante teria sido perdido por uma das vias citadas, mantendo-se estävel o seu teor conforme indicado na Figura 2.

Para o $\mathrm{N}^{-\mathrm{NO}_{3}^{-}}$(Tabela 6 e Figura 2), em nenhuma amostragem se observaram diferenças significativas entre os tratamentos com e sem $\mathrm{CaCO}_{3}$. A análise estatística do NMP de microrganismos nitrificadores, com os dados transformados em $\log (x+1)$, também não revelou efeito do $\mathrm{CaCO}_{3}$ sobre esse grupo de organismos, com exceção do tratamento $\mathrm{T}+\mathrm{C}+$ aos setenta dias de incubação. Esse fato não está de acordo com mui 
tos autores, que constataram aumento na nitrificação e na po pulação de nitrificadores com a adição de $\mathrm{CaCO}_{3}$ (EDMEADES et alii, 1981; NYBORG e HOYT, 1978; SARATHCHANDRA, 1978; WICKRA MASINGHE et $a$ lii, 1985), mas coincide com as conclusões a que chegaram SANDANAM et aliii (1978) e WEBER e GAINEY (1962), pa ra os quais não é só a adição de $\mathrm{CaCO}_{3}$, com o consequeuente au mento nos valores de $\mathrm{pH}$, que teria efeito direto sobre a nitrificação。

A análise estatistica somente revelou efeito de $\mathrm{CaCO}_{3}$ sobre a população de nitrificadores aos setentadias de incubação. O número desses organismos no tratamento $\mathrm{T}+\mathrm{C}+$ (Tabela 4), altamente discrepante dos outros encontrados em qualquer época ou em qualquer tratamento (média de ..2.968,5, com os seguintes valores para as três repetições: 5.833,3, $2.674,4$ e 397,7$)$, é o que ocasionou essa diferença, e para o quê não se encontram justificativas.

A Figura 3, reflexo quase direto das quantidạ des de $\mathrm{N}-\mathrm{NH}_{4}^{+}$, resume os efeitos da adição de torta de filtro e $\mathrm{CaCO}_{3}$ sobre o nitrogênio prontamente disponível às plantas, isto é, $\mathrm{N}-\mathrm{NH}_{4}^{+}+\mathrm{N}-\mathrm{NO}_{3}^{-}$.

Dez dias depois de sua incorporação ao solo, a torta de filtro propiciou imobilização do nitrogênio a par tir das formas amoniacal e nitrica. Depois de trinta dias de incubação, a adição de $\mathrm{CaCO}_{3}$ minimizou o efeito da imobiliza 
ção causada pela torta de filtro, sem contudo aboli-lo completamente. Havia maiores quantidades de $\mathrm{N}_{-} \mathrm{NH}_{4}^{+}+\mathrm{N}^{+} \mathrm{NO}_{3}^{-}$nos tratamentos com $\mathrm{CaCO}_{3}$, mas o nitrogênio continuou imobilizado em presença de torta. Os efeitos da torta e do $\mathrm{CaCO}_{3}$ per duraram até os noventa dias de incubação. Os efeitos observados, principalmente no teor de $\mathrm{N}-\mathrm{NH}_{4}^{+}$, entre os 0 e 10 dias e entre 30 e 50 dias, evidentes no tratamento T-C+, podem ser devidos a um estímulo sobre a mineralização do nitrogênio do solo. Isso não estaria em desacordo com STANFORD et alii (1974), que afirmam que a secagem como à que foi submetido o solo neste experimento pode aumentar grandemente a mi neralização do nitrogênio do próprio solo.

4.3. Efeito da torta de filtro e do $\mathrm{CaCO}_{3}$ sobre a mineralização e imobilização âo nitrogênio do solo e sobre a nitrificação, em presença de nitrogênio adicionado

Os resultados da estimativa dos números mais prováveis de microrganismos amonificadores estão na Tabela 8; para os nitrificadores, na Tabela 9. Os resultados das

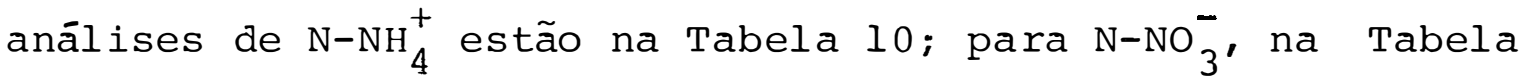
11 e para $\mathrm{N}^{-\mathrm{NH}_{4}^{+}}+\mathrm{N}_{4} \mathrm{NO}_{3}^{-}$, na Tabela 12. As Figuras 4, 5 e 6 representam as variações nos teores de $\mathrm{N}-\mathrm{NH}_{4}^{+}, \mathrm{N}-\mathrm{NO}_{3}^{-}$e $\mathrm{N}-\mathrm{NH}_{4}^{+}$ $+\mathrm{N}^{-\mathrm{NO}_{3}^{-}}{ }^{\prime}$ respectivamente. Os valores de $\mathrm{F}$ obtidos na análise estatística encontram-se nas Tabelas de 16 a 18, no Apêndice. 
Tabela 8 - Microrganismos amonificadores $\left(x 10^{5}\right)$ por grama de solo para as diferentes épocas de amostragem (médias de 3 repetições) (2\% experimento) .

\begin{tabular}{crrrr}
\hline \multirow{2}{*}{$\begin{array}{c}\text { DIAS } \\
\text { DE } \\
\text { INCUBAÇÃO }\end{array}$} & T R A T A M E N T O S* \\
\cline { 2 - 5 } & $1 . T-C-$ & $2 . T-C+$ & $3 . T+C-$ & $4 . T+C+$ \\
\hline 0 & 42,1 & $>180,0$ & 7,2 & 152,3 \\
10 & $>180,0$ & $>180,0$ & $>180,0$ & $>180,0$ \\
30 & 63,4 & $1.390,6$ & 273,3 & $1.521,4$ \\
50 & 144,9 & 442,4 & 500,3 & 299,1 \\
70 & 8,6 & 50,1 & 24,6 & 37,6 \\
90 & 38,0 & 123,9 & 187,9 & 34,1 \\
\hline
\end{tabular}

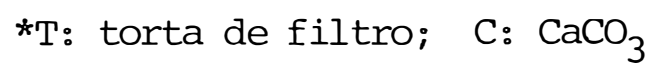

+: presença; -: ausência.

Tabela 9 - Microrganismos nitrificadores por grama de solo para as diferentes épocas de amostragem (média de 3 repetições) (2\% experimento).

\begin{tabular}{crrrr}
\hline \multirow{2}{*}{$\begin{array}{c}\text { DIAS } \\
\text { DE } \\
\text { INCUBAÇAO }\end{array}$} & \multicolumn{4}{c}{ T R A T A M E N T O S* } \\
\cline { 2 - 5 } & 1。T-C- & 2。T-C+ & 3.T+C- & 4。T+C+ \\
\hline 0 & 190,4 & 450,7 & 18,9 & 345,0 \\
10 & 20,8 & 7,1 & 5,5 & 12,8 \\
30 & 22,9 & 16,2 & 34,8 & 22,0 \\
50 & 19,0 & 8,0 & 5,5 & 34,3 \\
70 & 11,8 & 37,1 & 19,0 & 56,5 \\
90 & 20,7 & 14,3 & 24,7 & 34,1 \\
\hline
\end{tabular}

*T: torta de filtro; $\mathrm{C}: \mathrm{CaCO}_{3}$ +: presença; -: ausência. 


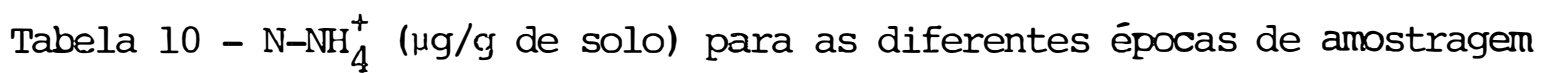
(médias de 3 repetições) (2: experimento).

\begin{tabular}{crrrr}
\hline $\begin{array}{c}\text { DIAS } \\
\text { DE } \\
\text { INCUBAÇÃ }\end{array}$ & \multicolumn{4}{c}{ T R A T A M E N T S* } \\
\cline { 2 - 5 } & $1 . \mathrm{T}-\mathrm{C}-$ & $2 . \mathrm{T}-\mathrm{C}+$ & $3 . \mathrm{T}+\mathrm{C}-$ & $4 . \mathrm{T}+\mathrm{C}+$ \\
\hline 0 & 54,8 & 78,4 & 82,1 & 72,2 \\
10 & 140,2 & 94,8 & 140,5 & 94,3 \\
30 & 144,5 & 114,5 & 139,7 & 124,1 \\
50 & 136,8 & 100,6 & 76,6 & 59,6 \\
70 & 99,0 & 66,3 & 84,6 & 55,3 \\
90 & 92,8 & 84,6 & 87,3 & 51,3 \\
\hline
\end{tabular}

*T: torta de filtro; $\mathrm{C}: \mathrm{CaCO}_{3}$

+: presença; -: ausência.

Tabela 11 - N-NO $\mathrm{N}_{3}^{-}(\mu \mathrm{g} / \mathrm{g}$ de solo) para as diferentes épocas de amostragem (médias de 3 repetiçōes) (20 experimento).

\begin{tabular}{crrrr}
\hline \multirow{2}{*}{$\begin{array}{c}\text { TIAS } \\
\text { INCUBAÇÃO }\end{array}$} & $1 . \mathrm{T}-\mathrm{C}-$ & $2 . \mathrm{T}-\mathrm{C}+$ & $3 . \mathrm{T}+\mathrm{C}-$ & $4 . \mathrm{T}+\mathrm{C}+$ \\
\cline { 2 - 5 } & 99,8 & 83,3 & 71,4 & 85,2 \\
0 & 113,4 & 101,6 & 127,9 & 124,2 \\
10 & 129,4 & 123,4 & 124,6 & 141,7 \\
50 & 121,5 & 128,2 & 87,2 & 83,3 \\
70 & 90,8 & 83,0 & 82,9 & 80,5 \\
90 & 87,6 & 114,7 & 81,2 & 84,2 \\
\hline
\end{tabular}

*T: torta de filtro; $\mathrm{C}: \mathrm{CaCO}_{3}$

t: presença; -: ausência. 
Tabela $12-\mathrm{N}_{-} \mathrm{NH}_{4}^{+}+\mathrm{N}-\mathrm{NO}_{3}^{-}(\mu \mathrm{g} / \mathrm{g}$ de solo) para as diferentes épocas de amostragem (médias de 3 repetições) (2: experimento).

\begin{tabular}{ccccc}
\hline \multirow{2}{*}{$\begin{array}{c}\text { DIAS } \\
\text { DE } \\
\text { INCUBAÇÄO }\end{array}$} & $1 . \mathrm{T}-\mathrm{C}-$ & $2 . \mathrm{T}-\mathrm{C}+$ & $3 . \mathrm{T}+\mathrm{C}-$ & $4 . \mathrm{T}+\mathrm{C}+$ \\
\hline & 154,6 & 161,7 & 153,4 & 157,3 \\
\hline 0 & 253,6 & 196,4 & 268,4 & 218,5 \\
10 & 273,9 & 237,8 & 259,6 & 266,8 \\
30 & 258,2 & 228,8 & 163,8 & 142,9 \\
50 & 189,8 & 149,3 & 167,5 & 135,8 \\
70 & 180,7 & 199,3 & 168,4 & 135,6 \\
90 & & & & \\
\hline
\end{tabular}

*T: torta de filtro; C: $\mathrm{CaCO}_{3}$

t: presença; -: ausência. 


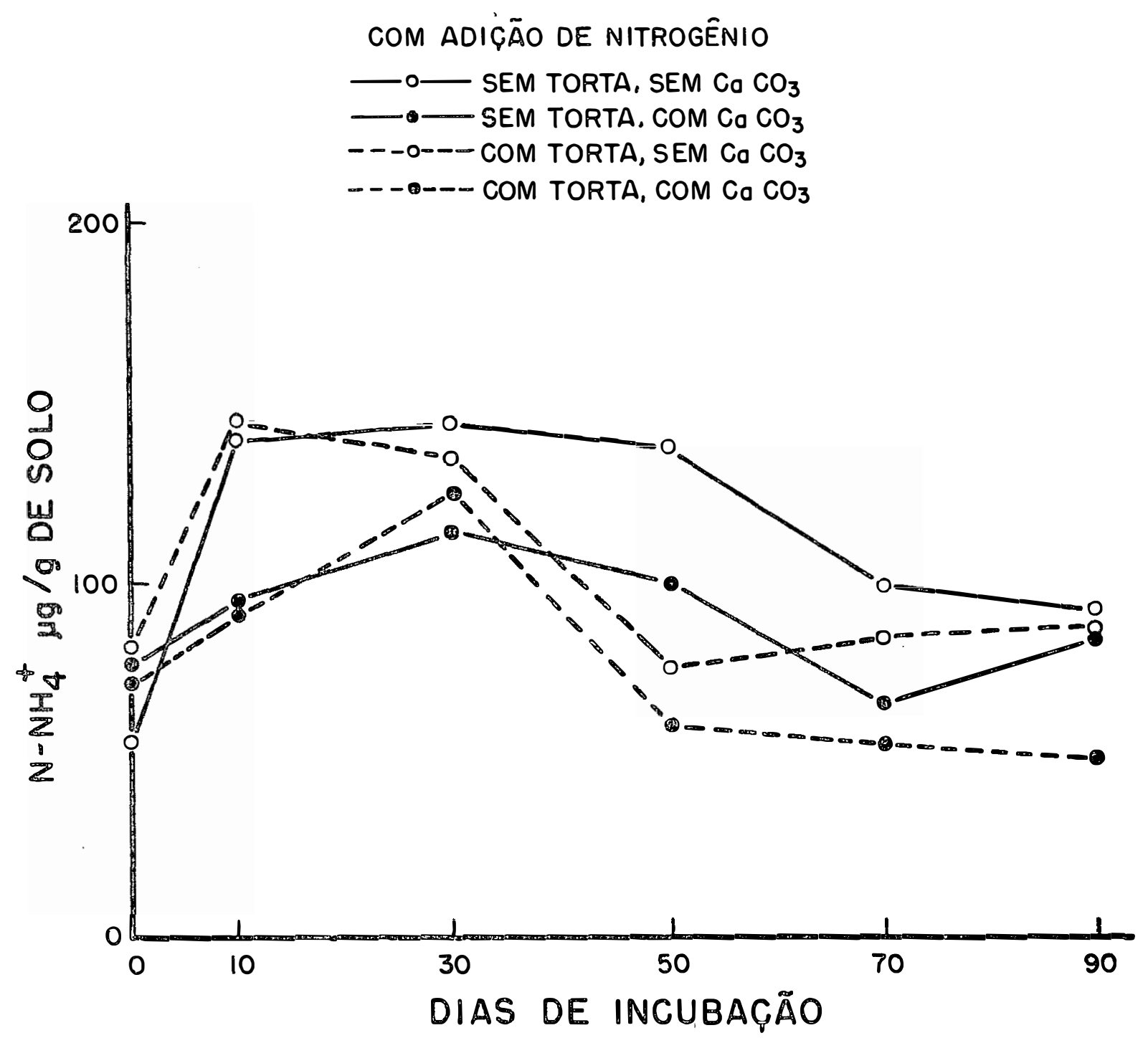

Figura $4-\mathrm{N}^{-\mathrm{NH}_{4}^{+}}$( $\mathrm{\mu g} / \mathrm{g}$ de solo) para os tratamentos e períodos de incubação indicados (médias de 3 repetições) (20 experimento). 
46.

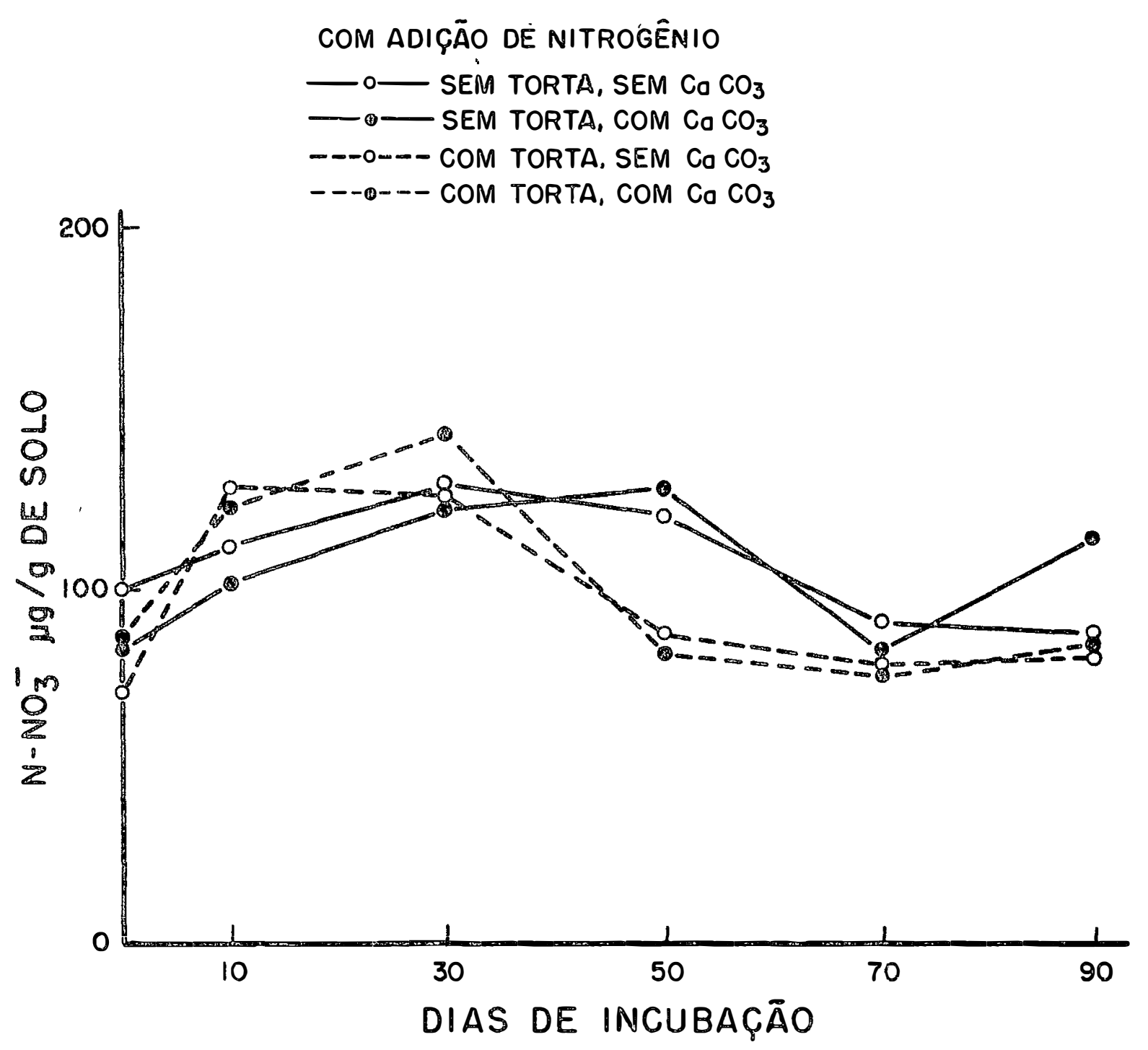

Figura $5-\mathrm{N}_{-} \mathrm{NO}_{3}^{-}$( $\mu \mathrm{g} / \mathrm{g}$ de solo) para os tratamentos e periodos de incuba ção indicados (médias de 3 repetições) (2\% experimento). 

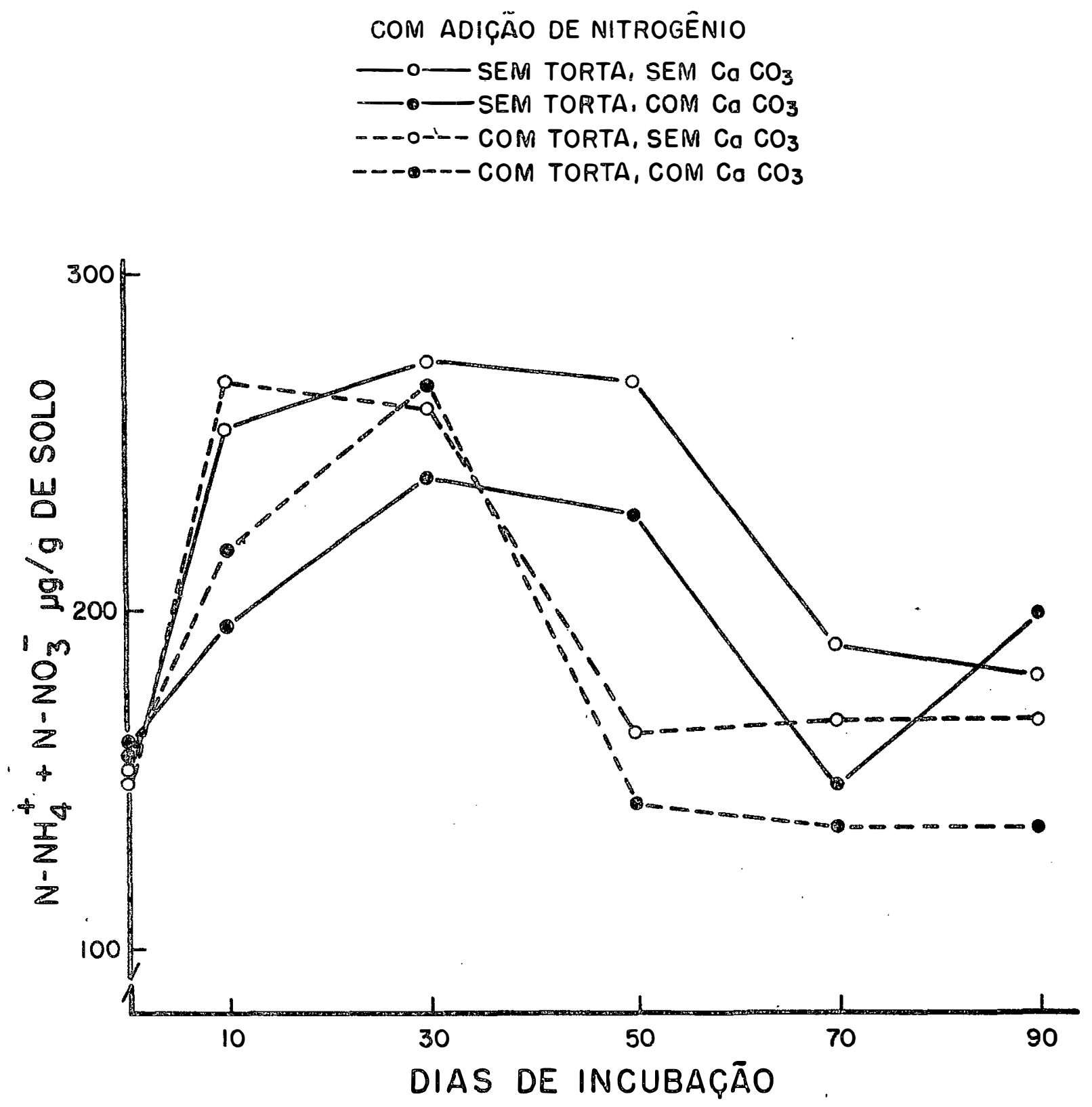

Figura $6-\mathrm{N}_{-} \mathrm{NH}_{4}^{+}+\mathrm{N}-\mathrm{NO}_{3}^{-}(\mu \mathrm{g} / \mathrm{g}$ de solo) para os tratamentos e períodos de incubação indicados (médias de 3 repetições) (2: experimento). 
Na primeira amostragem, para o tratamento T-C+, e na segunda amostragem, para todos os tratamentos, pelos mes mos motivos já expostoṣ quando da discussão dos resultados do experimento anterior, não foi possível determinar o NMP de microrganismos amonificadores (Tabela 8).

Apōs 10 dias de incubação, observou-se um aumento nos teores de $\mathrm{N}_{-} \mathrm{NH}_{4}^{+}$(Tabela 10 e Figura 4) dos tratamentos sem $\mathrm{CaCO}_{3}$, sendo esses teores significativamente dife rentes dos tratamentos $\operatorname{com} \mathrm{CaCO}_{3}$, não tendo havido efeito de torta de filtro. Já que não se pode comparar esses dados com O NMP de microrganismos amonificadores, pode-se apenas supor que a calagem, aliada à adição de nitrogênio, tenha estimula do de tal forma a microflora que ela tenha imobilizado o nitrogênio liberado na mineralização. Aliás, esse efeito do $\mathrm{CaCO}_{3}$, diminuindo o teor de $\mathrm{N}_{-} \mathrm{NH}_{4}^{+}$do solo, foi significativo em todas as épocas de amostragem, com exceção da primeira. Mesmo sem os nümeros de amonificadores aos 10 dias de incubação, é razoável supor-se esse estímulo do $\mathrm{CaCO}_{3}$ sobre a microflora, uma vez que aos 0 e 30 dias de incubação, para todos os tratamentos, e nas amostragens subsequientes, para os tratamentos sem torta, observa-se uma tendência de aumento no NMP de microrganismos amonificadores nos tratamentos que receberam $\mathrm{CaCO}_{3}$ (Tabela 8). 
Quanto à torta de filtro, só houve diferença significativa após 50 dias de incubação, o que não se manteve nas amostragens seguintes (Figura 4). A partir dessa mesma época, nota-se uma tendência de queda na população de amo nificadores. Esse fato, eventualmente diminuindo a quantidade de $\mathrm{N}-\mathrm{NH}_{4}^{+}$liberado pela mineralização e aliado ao aumento que se pode esperar da microflora como um todo, em presença de torta, pode explicar a imobilização do $\mathrm{N}-\mathrm{NH}_{4}^{+}$nessa época de amostragem. Depois dessa amostragem, ainda mantendo-se o efeito do $\mathrm{CaCO}_{3}$, hã uma tendência de estabilização das curvas (Figura 4) e de volta aos níveis iniciais de $\mathrm{N}^{-\mathrm{NH}_{4}^{+}}$. Quanto ao nitrato, em nenhuma amostragem se encontrou efeito significativo da adição de $\mathrm{CaCO}_{3}$ sobre os teores desse íon. À semelhança do que ocorreu no experimento anterior, não se confirmou aqui o esperado efeito estimulante do $\mathrm{CaCO}_{3}$, ou seja, da elevação dos valores de pH em āgua (foi, em média, de 4,0, nos tratamentos sem $\mathrm{CaCO}_{3}$, e de 6,7, nos com $\mathrm{CaCO}_{3}$ ), sobre a nitrificação, lembrando, novamente, os trabalhos de SANDANAM et a $7 i i$ (1978) e WEBER e GAINEY (1962), que concluíram que não é só o $\mathrm{CaCO}_{3}$ que tem efeito direto sobre a nitrificação.

Entretanto, aos dez dias de incubação, houve efeito significativo da torta sobre os teores de nitrato, au mentando os teores desse íon (Tabela 11, Figura 5). É inte- 
50.

ressante lembrar que, nessa mesma amostragem, não houve efei to da torta sobre o teor de amônio. Pode-se pensar então que a torta teve efeito diretamente sobre a nitrificação, ainda que isso contradiga os resultados obtidos por SCHERER e MENGEL (1981), os quais observaram que $\circ \mathrm{NO}_{3}^{-}$do solo foi sempre significativamente menor nos tratamentos com incorporação de palha que nos sem palha.

Aos 30 dias de incubação não se observaram quaisquer diferenças significativas entre os quatro tratamen tos. Aos 50 dias de incubação houve efeito de torta, diminuindo o teor de $\mathrm{N}^{-\mathrm{NO}_{3}^{-}}$no solo (Tabela 11 e Figura 5). Na mesma época também houve esse efeito sobre o teor de $\mathrm{N}_{-} \mathrm{NH}_{4}^{+}$ (Tabela 10 e Figura 4), conforme o que já foi discutido. As sim, em virtude da ocorrência da imobilização do $\mathrm{N}^{-\mathrm{NH}_{4}^{+}}$causa da pelatorta, é plenamente justificável a diminuição no teor de $\mathrm{N}^{-\mathrm{NO}_{3}^{-}}$' seja pela imobilização desse ín, seja pela remoção do $\mathrm{N}^{-\mathrm{NH}_{4}^{+}}$, substrato para a nitrificação.

A Tabela 12 e Figura 6 resumem os os efeitos a adição de torta de filtro e de $\mathrm{CaCO}_{3}$, em presença de nitrogê nio adicionadb, sobre as quantidades de $\mathrm{N}^{-\mathrm{NH}_{4}^{+}}+\mathrm{N}^{-} \mathrm{NO}_{3^{-}}^{-}$ou seja, de nitrogênio prontamente disponível. Aos 10 dias de incubação houve efeito de $\mathrm{CaCO}_{3}$ diminuindo o teor de nitrogênio $\left(\mathrm{N}^{-} \mathrm{NH}_{4}^{+}+\right.$ $\mathrm{N}-\mathrm{NO}_{3}^{-}$), efeito esse novamente detectaỏ aos 70 dias. E interessante 
lembrar que aqui, diferentemente do que ocorreu no experimen to anterior, $\mathrm{O} \mathrm{CaCO}_{3}$, quando agiu sobre o teor de nitrogênio no solo, fē-lo no sentido de diminuir esse teor. Aos 50 e aos 90 dias de incubação somente é que a torta teve efeito sobre a disponibilidade de nitrogênio, diminuindo-a pela imobilização. 
52.

5. CONCLUSÖES

Os resultados obtidos neste trabalho permitem concluir o seguinte:

1. A torta de filtro, isoladamente, determinou imobilização do nitrogênio do solo. A suplementação do solo com $\mathrm{NH}_{4} \mathrm{NO}_{3}$ impediu a imobilização, que só foi observada aos 50 e aos 90 dias de incubação.

2. A adiçäo de $\mathrm{CaCO}_{3}$ diminuiu a magnitude da imobilização de nitrogênio quanco esse nutriente não foi aplicado, mas exerceu pouco efeito na presença de $\mathrm{N}$ adicionado . 
53.

3. A adição de $\mathrm{CaCO}_{3}$ não teve efeito sobre a nitrificação.

4. Experimentos com microrganismos nitrificadores em meio de cultura devem ser conduzidos em ausência de luz. 
6. LITERATURA CITADA

ALEXANDER, M。, 1961. Introduction to soil. microbiology. No va York, John Wiley \& Sons. $472 \mathrm{p}$.

ALEXANDER, M。, 1971. Microbial Ecology. John Wiley \& Sons, Inc. $511 \mathrm{p}$.

ALLEN, O.N., 1949. Experiments in Soil Bacteriology。 Burgess Publishing Co., Minneapolis. $126 \mathrm{p}$.

AMER, F.M。 e W.V. BARTHOLOMEW, 195l。 Influence of oxygen concentrations in soil air on nitrification. Soil Science, 71: 215-219。

ANDERSON, O.E. E F.C. BOSWELL, 1964. The influence of low temperature and various concentrations of ammonium nitrate on nitrification in acid soils. Soil Science Society of America Proceedings, 28: 525-529. 
ASGHAR, M。 e Y. KANEHIRO, 1976. Effects of sugarcane trash and pineapple residue incorporation on soil nitrogen, $\mathrm{pH}$ and redox potential. Plant and Soil; $\underline{44}$ : 209-218.

BARTHOLOMEW, W.V., 1965. Mineralization and immobilization of nitrogen in the decompositon of plant and animal residues. In: BARTHOLOMEW, W.V. e F.E. CLARK (eds.) Soil Nitrogen. Agronomy Series 10, American Society of Agronomy, Inc., Madison, p.285-306。

BARTHOLOMEW, W.V. e F.E. CLARK (eds.), 1965. Soil Nitrogen. Agronomy Series 10, American Society of Agronomy, Inc., Madison, $615 \mathrm{p}$.

BREMNER, J.M., 1965. Inorganic forms of nitrogen. In: BLACK, C.A. (ed.). Methods of soil analysis. Part II. American Society of Agronomy. Madison, p。1179-1237.

BROADBENT, F.E. e T. NAKASHIMA, 1970。 Nitrogen immobilization in flooded soils. Soil Science Society of America. Proceedings, 34: 2il8-221。

BROADBENT, F.E。 e T. NAKASHIMA, 1974. Mineralization of car bon and nitrogen in soil amended with carbon-13 and nitro gen-15 labeled plant material. Soil science society of America Proceedings, 38: 313-315.

BROADBENT, F.E.; K.B. TYLER e G.N.HILL, 1957. Nitrification of ammoniacal fertilizers in some California soils. Hilgardia, 27: 247-267. 
56.

BUCKMAN, H.O. e N.C. BRADY, 1967. Natureza e Propriedades. dos Solos. USAID/Livraria Freitas Bastos, Rio de Janeiro. $549 \mathrm{p}$.

CASSMAN, K.G. e D.N.MUNN, 1980. Nitrogen mineralization as affected by soil moisture, temperature and depth. Soil Science Society of America Journal, 44: 1233-1237.

COPERSUCAR (s.d.). Uso da torta de filtro no plantio da cana-de-açúcar. Cadernos COPERSUCAR, Série Agronômica 1,Cen tro de Tecnologia COPERSUCAR, São Paulo, 5 p.

CRASWELL, E.T., 1978. Some factors influencing denitrification and nitrogen immobilization in a clay soil. Soil Biology \& Biochemistry, 10: 241-245.

DOMMERGUES, Y. e F. MANGENOT, 1970. Écologia Microbienne du Sol. Masson et Cie., Paris, 796 p.

EDMEADES, D.C.; M. JUDD e S.U. SARATHCHANDRA, 1981. The effect of lime on nitrogen mineralization as measured by grass growth. Plant and Soil, 60: 177-186.

ERIKSSON, E., 1952. Composition of atmospheric precipitation. I. Nitrogen compound. Tellus, 4: 215-232.

FORTUN, C.e V. HERNANDO, 198la. Efecto de la paja y de dis tintos niveles de nitrógeno en el desarrollo de la cebada. Anales de Edafología y Agrobiología, XL: 1205-1215.

FORTUN, C。e V。HERNANDO, 1981b. Aprovechamiento de la paja como abono orgánico en um cultivo de sorgo. Anales de Edafología y Agrobiologí, XL: 1227-1234. 
GANRY, F。; G. GUIRAUD e Y. DOMMERGUES, 1978. Effect of straw incorporation on the yield and nitrogen balance in the san dy soil-pearl millet cropping system of Senegal. Plant and Soil, 50: 647-662.

HALVORSON, H.O. e N.R. ZIEGLER, 1932. Application of statistics to problems in bacteriology. I. A means of determining bacterial population by the dilution method. Journal. of Bacteriology, XXV: 101-121.

ISHAQUE, M. e M.H. CORNFIELD, 1974. Nitrogen mineralization and nitrification in relation to incubation temperature in an acid Bangladesh soil lacking autotrophic nitrifying organisms. Tropical Agriculture, 51: 37-4l.

JENSEN, H.L., 1929. On the influence of the carbon: nitrogen ratios of organic material on the mineralization of nitrogen. The Journal of Agricultural Science, 19: 71-82.

JOHNSON, D.D. e W.D. GUENZIE, 1963. Influence of salts on ammonium oxidation and carbon dioxide evolution from soil. Soil Science Society of America Proceedings, 27: 663-666.

KANAMORI, T. e T. YASUDA, 1979. Immobilization, mineralization and the availability of the fertilizer nitrogen during the decomposition of the organic matters applied to the soil. Plant and Soil, 52: 219-227.

LEES, H. e J.H. QUASTEL, 1946. Biochemistry of nitrification in soils. I. Kinetics of, and the effects of poison on soil nitrification as studied by a soil perfusion technique. Biochemical Journal, 40: 803-815. 
LEUKEN, H。; W.L. HUTCHEON e E.A. PAUL, 1962. The influence of nitrogen on the decomposition of crop residues in the soil. Canadian Journal of Soil Science, 42: 276-288.

MARTIKAINEN, P.J., 1985. Numbers of autotrophic nitrifiers and nitrification in fertilized forest soil. Soil Biology and Biochemistry, 17: 245-248.

MUNDRA, M.C.; G.S. BHANDARI e O.P.SRIVASTAVA, 1973. Studies on mineralization and immobilization of nitrogen in soil. Geoderma, 9: 27-33.

MYERS, R.J.K.; C.A. CAMPBELL e K.L。WEIR, 1982. Quantitati ve relationship between net nitrogen mineralization and moisture content of soils. Canadian Journal of Soil Science, 62: 111-124.

NAFTEL, J.A., 1931. The nitrification of ammonium sulphate as influenced by soil reaction and degree of base satura tion. Journal of the American Society of Agronomy, 23: $175-185$.

NYBORG, M. e P.B. HOYT, 1978. Effects of soil acidity and liming on mineralization of soil nitrogen. Canadian Journal of Soil Science, 58: 331-338.

POCHON, J。e P. TARDIEUX, 1962. Technigues d'analyse in microbiologia du sol. Ed. de la Tourelle. França.

PRAMER, D。e E.L. SCHMIDT, 1964。 Experimental Soil Microbiology. Burgess Publishing Co., Minneapolis. 
PREMI, P.R。 e A.H. CORNFIELD, 1969. Effects of addition of copper, manganese, zinc and chromium compounds on ammonification and nitrification during incubation of soil. Plant and soil, 31: 345-352.

SANDANAM, S。; S。KRISHNAPILLAI e J。 SABARATNAM, 1978。 Nitri fication of ammonium sulphate and urea in an acid red yellow podzolic tea soil in Sri Lanka in relation to soil fer tility. Plant and Soil., 49: 9-22.

SARATHCHANDRA, S.U., 1978. Nitrification activities and the changes in soil perfused at two different H-ion concentra tions. Plant and Soil, 50: 99-11l.

SCHERER, H.W. e K. MENGEL, 1981. The effect of a straw application on the content of nitrate and exchangeable ammo nium in the soil and on the yield and nitrogen uptake of Italian ryegrass (Lolium multiflorum). Landwirtschaftliche Forschung, 34: 194-205. [Abstract].

SCHMIDT, E.L。e L.W.BELSER, 1982. Nitrifying bacteria. In: Methods of Soil Analysis. Part 2. Chemical and Microbiological Properties. Agronomy Monograph no 9 (2a ed。) ASA-SSSA, Madison, p.1027-1042。

STANFORD, G。; J.N.CARTER e S.J.SMITH, 1974. Estimates of potentially mineralizable soil nitrogen based on short-term incubations. Soil Science Society of America Proceedings, 38: 99-102. 
STOJANOVIC, B.J.e F.E.BROADBENT, 1956. Immobilization and mineralization rates of nitrogen during decomposition of plant residues. Soil Science Society of America Procee-. dings, 20: 213-218.

TAM, R.K。 e O.C.MAGISTAD, 1936. Chemical changes during decomposition of pineapple trash under field condition. Soil Science, 41: 315-327.

VAN VEEN, J.A. e E.A.PAUL, 1979. Conversion of biovolume measurements of soil organisms, grown under various moisture tensions, to biomass and their nutrient content. Applied and Environmental Microbiology, 37: 686-692.

VENKATAKRISHNAN, S。, 1980。 Mineralization of green manure (Sesbania aculeata, Pers.) nitrogen in sodic and reclaimed soils under flooded conditions. Plant and Soil, 54: 149-152 .

VIRTANEN, A.I., 1952. Molecular nitrogen fixation and nitro gen cycle in nature. Tellus, $\underline{4}:$ 304-306.

WEBER, D.F。e P.L.GAINEY, 1962. Relative sensitivity of nitrifying organisms to hydrogen ions in soils and solutions. Soil Science, 94: 138-148.

WICKRAMASINGHE, K.N。; G.A。RODGERS e D.S。JENKINSON, 1985. Nitrification in acid tea soils and a neutral grassland soil: effects of nitrification inhibitors and inorganic salts. Soil Biology \& Biochemistry, 17: 249-252. 
WÖJCIK-WOJTKOWIAK, D., 1978. Nitrogen transformations in soil during humification of straw labelled with ${ }^{15} \mathrm{~N}$. Plant and Soil, 49: 49-55. 
62.

7. APENDICE 
Tabela 13 - Valores obtidos no teste F na análise do efeito de torta de filtro e de $\mathrm{CaCO}_{3}$ sobre o teor de $\mathrm{N}-\mathrm{NH}_{4}^{+}$no solo (experimento sem ađ̉ição de N) .

\begin{tabular}{ccccccc}
\hline & \multicolumn{6}{c}{ AMOSTRAGEM (dias) } \\
\cline { 2 - 7 } & 0 & 10 & 30 & 50 & 70 & 90 \\
\hline Torta (T) & 0,81 & $34,36 * *$ & $14,00 * *$ & $29,80 * *$ & $7,29 *$ & $7,47 * *$ \\
$\mathrm{CaCO}_{3}$ (C) & $11,17 * *$ & $11,38 * *$ & $18,54 * *$ & $20,52 * *$ & $24,36 * *$ & $19,05 * *$ \\
Interação TxC & 0,94 & $12,71 * *$ & 0,82 & $8,56 * *$ & 4,72 & 5,45 \\
\hline Significância a 5\% (*) e a 1\% (**).
\end{tabular}

Tabela 14 - Valores obtidos no teste $\mathrm{F}$ na análise do efeito de torta de filtro e de $\mathrm{CaCO}_{3}$ sobre o teor de $\mathrm{N}-\mathrm{NO}_{3}^{-}$no solo (experimento sem adição de $\mathrm{N}$ ) .

\begin{tabular}{ccccccc}
\hline & \multicolumn{7}{c}{ AMOSTRAGEM } & (dias) \\
\cline { 2 - 6 } & 0 & 10 & 30 & 50 & 70 & 90 \\
\hline EFEITO & 4,84 & $11,66 * *$ & $23,57 * *$ & $26,92 * *$ & $26,96 * *$ & $23,39 * *$ \\
$\mathrm{CaCO}_{3}$ (C) & 3,48 & 0,52 & 0,41 & 0,40 & 0,14 & 0,75 \\
Interação TxC & 0,18 & 2,22 & 0,55 & 1,48 & 4,62 & 4,11 \\
\hline
\end{tabular}

Significância a 5\% (*) e a 1\% (**). 
Tabela 15 - Valores obtidos no teste $F$ na análise do efeito de torta de filtro e de $\mathrm{CaCO}_{3}$ sobre o teor de $\mathrm{N}-\mathrm{NH}_{4}^{+}+\mathrm{N}-\mathrm{NO}_{3}^{-}$no solo (experimento sem adição de N) .

\begin{tabular}{lcccccc}
\hline & \multicolumn{7}{c}{ AMOSTRAGEM (dias) } \\
\cline { 2 - 6 } & 0 & 10 & 30 & 50 & 70 & 90 \\
\hline Torta (T) & 4,04 & $46,81 * *$ & $30,67 * *$ & $56,91 * *$ & $24,87 * *$ & $23,05 * *$ \\
CaCO $_{3}$ (C) & 3,79 & $7,89 * *$ & $15,03 * *$ & $11,64 * *$ & $15,02 * *$ & $11,58^{* *}$ \\
Interação TxC & 0,26 & $10,95^{* *}$ & 1,23 & 2,56 & 0,25 & 0,49 \\
\hline
\end{tabular}

Significāncia a 5\% (*) e a 1\% (**) 。

Tabela 16 - Valores obtidos no teste $F$ na análise do efeito de torta de filtro e de $\mathrm{CaCO}_{3}$ sobre o teor de $\mathrm{N}-\mathrm{NH}_{4}^{+}$no solo (experimento com adição de $\dot{N}$ ) .

\begin{tabular}{lcccccc}
\hline & \multicolumn{7}{c}{ AMOSTRAGEM (dias) } \\
\cline { 2 - 6 } EFEITO & 0 & 10 & 30 & 50 & 70 & 90 \\
\hline Torta (T) & 1,00 & 0,0001 & 0,002 & $23,12^{* *}$ & 1,45 & 3,46 \\
$\mathrm{CaCO}_{3}$ (C) & 0,42 & $18,95^{* *}$ & $3,54 *$ & $6,39 *$ & $8,69 * *$ & $4,46^{*}$ \\
Interação TxC & 2,53 & 0,001 & 0,94 & 0,84 & 0,03 & 1,71 \\
\hline
\end{tabular}

Significância a 5\% (*) e a 1\% (**) 。 
Tabela 17 - Valores obtidos no teste $\mathrm{F}$ na análise do efeito de torta de filtro e de $\mathrm{CaCO}_{3}$ sobre o teor de $\mathrm{N}-\mathrm{NO}_{3}^{-}$no solo (experimento com adição de N) 。

\begin{tabular}{ccccccc}
\hline & \multicolumn{7}{c}{ AMOSTRAGEM } & (dias) \\
\cline { 2 - 7 } EFEITO & 0 & 10 & 30 & 50 & 70 & 90 \\
\hline Torta (T) & 2,43 & $4,73 *$ & 0,38 & $21,49 * *$ & 0,23 & 4,67 \\
CaCO $_{3}$ (C) & 0,01 & 0,51 & 0,26 & 0,02 & 0,22 & 3,13 \\
Interação TxC & 3,14 & 0,14 & 1,83 & 0,24 & 0,06 & 1,98
\end{tabular}

Significância a 5\% (*) e a 1\% (**).

Tabela 18 - Valores abtidos no teste $\mathrm{F}$ na análise do efeito de torta de filtro e de $\mathrm{CaCO}_{3}$ sobre o teor de $\mathrm{N}-\mathrm{NH}_{4}^{+}+\mathrm{N}-\mathrm{NO}_{3}^{-}$no solo lex perimento com adição de $\mathrm{N}$ ) .

\begin{tabular}{lcccccc}
\hline & \multicolumn{7}{c}{ AMOSTRAGEM (dias) } \\
\cline { 2 - 7 } & 0 & 10 & 30 & 50 & 70 & 90 \\
\hline Torta (T) & 0,03 & 1,26 & 0,22 & $30,04 * *$ & 1,19 & $5,34 *$ \\
CaCO $_{3}$ (C) & 0,13 & $10,60 * *$ & 0,87 & 2,34 & $4,82^{*}$ & 0,22 \\
Interação TxC & 0,01 & 0,06 & 1,75 & 0,08 & 0,08 & 2,45 \\
\hline
\end{tabular}

Significância a 5\% (*) e a 1\% (**) 。 